\title{
Effect of Frequency, Environment, and Temperature on Fatigue Behavior of E319 Cast-Aluminum Alloy: Small-Crack Propagation
}

\begin{abstract}
X. ZHU, J.W. JONES, and J.E. ALLISON
The influence of test frequency on fatigue-crack propagation behavior of small cracks in E319 cast-aluminum alloy was studied using ultrasonic and conventional test techniques. It was observed that fatigue cracks grow faster at $30 \mathrm{~Hz}$ than at $20 \mathrm{kHz}$ in air at both $20{ }^{\circ} \mathrm{C}$ and $250{ }^{\circ} \mathrm{C}$. The effect of frequency on the fatigue-crack growth rates was attributed to an environmental effect. For E319 cast-aluminum alloy, fatigue-crack growth rate increases with increasing water exposure (characterized by the ratio of water partial pressure over test frequency, $P(f)$, and this behavior can be estimated using a modified superposition model. The effect of temperature on fatigue-crack growth behavior was primarily attributed to the effect of temperature on Young's modulus and yield strength. The environmental contribution to fatigue-crack growth rates modestly decreases with increasing temperature.
\end{abstract}

DOI: $10.1007 / \mathrm{s} 11661-008-9630-2$

(C) The Minerals, Metals \& Materials Society and ASM International 2008

\section{INTRODUCTION}

Cast-Aluminum alloys have been extensively used in the production of fatigue- critical automotive components, including engine blocks and cylinder heads, which experience more than $10^{8}$ alternating stress cycles during the expected service life, and the very highcycle fatigue properties are therefore of great interest. Performing fatigue tests in the very high-cycle regime becomes practical with the use of ultrasonic-testing instrumentation, which operates at approximately $20 \mathrm{kHz}$. Ultrasonic-fatigue techniques can also be used for rapid generation of fatigue-crack growth data and offers the possibility to study very low fatigue-crack growth rates far below the conventional threshold $\left(10^{-10} \mathrm{~m} /\right.$ cycle $)$. However, in actual components of castaluminum alloys, the critical locations are subjected to a loading frequency of 20 to $100 \mathrm{~Hz}$, which is two to ten decades lower than the ultrasonic-fatigue testing frequency. Therefore, it is necessary to know if the fatigue properties are significantly influenced by the substantial increase in the cycling frequency.

Fatigue-damage evolution can be divided into crack initiation and crack propagation. It has been widely concluded that, for cast-aluminum alloys, fatigue cracks initiate predominantly from pores located at or close to the specimen surface, and the number of cycles required to initiate a crack is insignificant relative to the total fatigue life. Therefore, the fatigue life is dominated by

X. ZHU, Postdoctoral Research Fellow, and J.W. JONES, Professor, are with the Department of Materials Science and Engineering, University of Michigan, Ann Arbor, MI 48109. Contact email: zhux@umich.edu J.E. ALLISON, Senior Technical Leader, is with the Research \& Advanced Engineering, Ford Motor Company, Dearborn, MI 48124.

Manuscript submitted on September 10, 2007.

Article published online August 21, 2008 crack propagation in cast-aluminum alloys ${ }^{[1-4]}$ and determining the effect of frequency on fatigue-crack propagation is important in understanding the effect of frequency on the S-N behavior.

The effect of frequency on fatigue-crack propagation in aluminum alloys may arise from intrinsic effects, i.e., strain-rate effect, and time-dependent, or extrinsic, effects, such as those attributable to environmentally assisted crack growth or fatigue/creep interaction. It is unlikely that strain rate exerts a significant influence on fatigue-crack propagation in aluminum alloys because plastic deformation of face centered cubic metals has been reported to be relatively insensitive to strain rates. ${ }^{[5-7]}$ Holper et al. ${ }^{[8,9]}$ investigated the effect of frequency on fatigue-crack growth of aluminum alloys at $20 \mathrm{kHz}$ and $20 \mathrm{~Hz}$ in vacuum and found no frequency influence on near threshold fatigue-crack growth in aluminum alloys. Also, cyclic loading near the fatigue limit or fatigue-crack growth near the threshold stress intensity involves only minimal cyclic plastic deformation, thus strain-rate effects should be significantly moderated or absent. ${ }^{[8,9]}$

When the effect of strain rate is small, a dependence of crack-growth rate on frequency is expected to be related to environmental influences. It has been observed that the fatigue-crack growth threshold decreased and fatigue-crack growth rate increased in the presence of water vapor in atmospheric air for aluminum alloys. ${ }^{[10-17]}$ Because the duration of crack-tip opening under ultrasonic-frequency loading at $20 \mathrm{kHz}$ is an order of magnitude shorter for each cycle than for conventional fatigue experiments, any environmentally assisted increase in fatigue-crack growth rate is generally presumed to be less pronounced at $20 \mathrm{kHz}$, leading to lower fatigue-crack growth rate at this frequency. Holper et al. ${ }^{[9]}$ studied the influence of frequency on fatiguecrack growth of aluminum alloys and reported that 
fatigue cracks propagated at lower growth rates at $20 \mathrm{kHz}$ than at $20 \mathrm{~Hz}$ in ambient air if cycled above threshold; however, the test frequency had no influence on the fatigue-crack growth threshold itself.

In this article, the fatigue-crack propagation behavior of a 319-type cast-aluminum alloy (referred to as E319) was studied at ultrasonic and conventional cyclic frequencies at $20{ }^{\circ} \mathrm{C}$ and $250{ }^{\circ} \mathrm{C}$ to understand the potential effect of frequency and environment at ambient and elevated temperature. In a companion article, ${ }^{[18]}$ the effect of frequency, environment, and temperature on S-N behavior of E319 cast-aluminum alloy will be addressed in detail.

\section{EXPERIMENTAL}

\section{A. Material}

The E319 cast-aluminum alloy examined in this study has a nominal composition of (by wt pet) $7.61 \mathrm{Si}$, $3.28 \mathrm{Cu}, 0.22 \mathrm{Mg}, 0.33 \mathrm{Mn}, 0.70 \mathrm{Fe}, 0.65 \mathrm{Zn}, 0.11 \mathrm{Ti}$, $0.02 \mathrm{Ni}, 0.012 \mathrm{Sr}$, and balance Al. Aluminum plates were cast using sand molds, and rectangular bars were sectioned from each plate in the region with an average secondary dendrite arm spacing (SDAS) of $30 \mu \mathrm{m}$. Figure 1 shows the typical microstructure of the cast E319 alloy, which consists of primary $\alpha$-aluminum dendrites, Al-Si eutectic, and intermetallics. As shown in Figure 1, SDAS was measured as the distance between centers of two adjacent secondary dendrite arms. At least 50 measurements were made on an area of

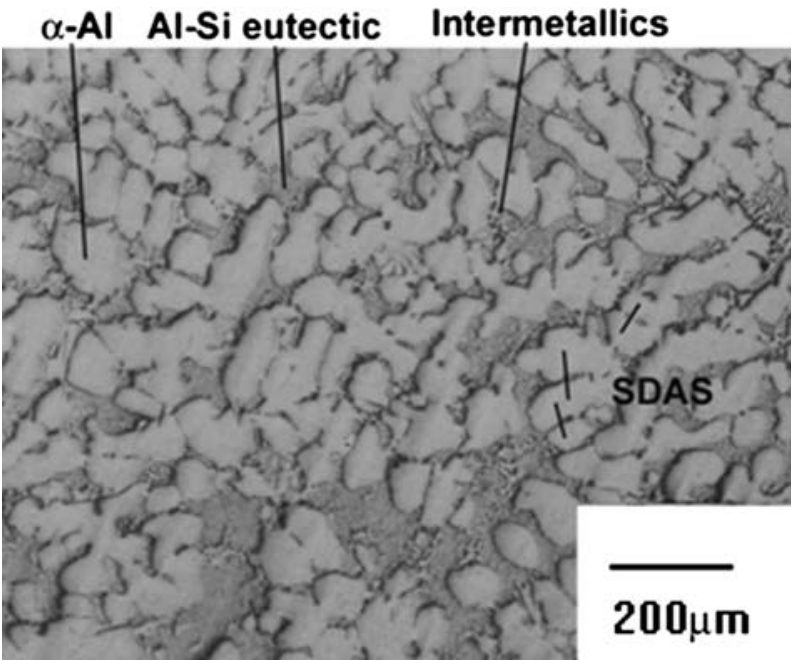

Fig. 1-Microstructure of E319 cast-aluminum alloy from the sectioned region. Note the short lines illustrate the measurement of SDAS.
$400 \mathrm{~mm}^{2}$ to ensure that a sufficient number of dendrite arms were counted for meaningful quantitative analysis. Subsequently, the bars were hot isostatically pressed (HIP) at $480{ }^{\circ} \mathrm{C}$ and $105 \mathrm{MPa}$ for 3 hours to reduce the shrinkage porosity to insignificant levels. The HIP bars were then subjected to a T7 overaged heat treatment, consisting of solution heat treatment at $495{ }^{\circ} \mathrm{C}$ for 8 hours, followed by water quench at $90{ }^{\circ} \mathrm{C}$ and aging at $260{ }^{\circ} \mathrm{C}$ for 4 hours. A $90{ }^{\circ} \mathrm{C}$ water quench after solution treatment is a standard industrial process for heat treatment of cast engine blocks, for which this alloy is commonly used. The milder quench is used to reduce the possibility of cracking during quenching of these complicated parts and to reduce the level of residual stresses produced during quenching.

The tensile properties of E319-T7 at ambient and elevated temperatures were obtained by testing the material per ASTM E21-03a and ASTM E8-04. The results are summarized in Table I. It should be pointed out that the dynamic Young's modulus, instead of the static Young's modulus from tensile tests, was measured during cyclic fatigue testing. These values were taken from Reference 16, in which specimens from the same heat of $319 \mathrm{Al}$ were cycled under load control between -30 and $30 \mathrm{MPa}$ for 20 cycles at $1 \mathrm{~Hz}$ at room temperature. A linear equation is interpolated for all points at each cycle, and the average slope of the 20 measurements gives the elastic modulus at the corresponding temperature. The same procedure was conducted at elevated temperatures, and the modulus was found to vary with temperature following the empirical equation, which is valid from $20{ }^{\circ} \mathrm{C}$ to $300{ }^{\circ} \mathrm{C}$ :

$$
E(\mathrm{GPa})=78.5-0.05 \times T\left({ }^{\circ} \mathrm{C}\right)
$$

Fatigue specimens (Figure 2) were machined from the heat-treated bars. All specimens have cylindrical gage sections with a 5-mm diameter and 15-mm length. To ensure consistent surface finish with low residual stress, samples were machined using low-stress turning at Westmoreland Mechanical Testing \& Research (Youngstown, PA).

\section{B. Fatigue Testing}

Ultrasonic-fatigue tests were conducted in lab air at $20{ }^{\circ} \mathrm{C}$ and $250{ }^{\circ} \mathrm{C}$ using fully reversed tension-compression loadings $(R=-1)$. The specimen (Figure 3 ) vibrates in resonance at approximately $20 \mathrm{kHz}$, producing a displacement distribution with maximum amplitude at both ends and a vibration node in the center of the specimen. The strain amplitude along the length of the specimen has a maximum value in the center, and

Table I. Yield Strength, Tensile Strength, Elongation, and Dynamic Young's Modulus of E319 Cast Aluminum at $2{ }^{\circ} \mathrm{C}, 150{ }^{\circ} \mathrm{C}$, and $250{ }^{\circ} \mathrm{C}$

\begin{tabular}{lcccc}
\hline Temperature $\left({ }^{\circ} \mathrm{C}\right)$ & Yield Strength $(\mathrm{MPa})$ & Tensile Strength $(\mathrm{MPa})$ & Elongation $(\mathrm{Pct})$ & Young's Modulus $(\mathrm{GPa})$ \\
\hline 20 & 199 & 290 & 2 & 77.5 \\
150 & 181 & 223 & 5 & 71 \\
250 & 123 & 147 & 7 & 66 \\
\hline
\end{tabular}




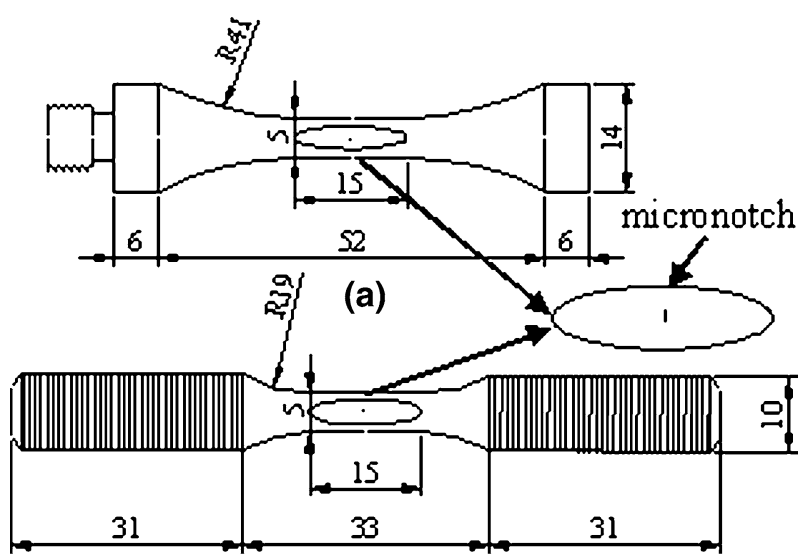

(b)

Fig. 2-Specimen geometry used for fatigue-crack growth tests at $(a)$ $20 \mathrm{kHz}$ and $(b) 30 \mathrm{~Hz}$ at $R=-1$. Dimensions are in milimeters. Laser-machined micronotches in the gage section of the specimens are schematically shown.

the strain in the gage length was held constant to within 5 pct. The strain in the gage section was calibrated against the input power signal using strain gages. The resulting calibration curve was used to arrive at the power input to the ultrasonic transducer to produce the target strains. Stresses were derived, assuming linear elasticity. These results were verified by noncontact specimen displacements measured by using an optical sensor and further confirmed by finite-element analysis. More details of the ultrasonic-testing methodology can be found in References 4 and 19 through 21. The ultrasonic loading is applied in well controlled pulses ( $200 \mathrm{~ms}$ on/800 ms off) to reduce specimen heating. Specimen temperature was measured with thermocouple after a number of cycles, and the temperature change is within $5{ }^{\circ} \mathrm{C}$. An induction-heating technique was used for ultrasonic-fatigue testing at $250{ }^{\circ} \mathrm{C}$ (Figure 3(a)).

For comparison, conventional fatigue tests were conducted at $30 \mathrm{~Hz}$ using servohydraulic fatigue-testing equipment under load control. Fatigue testing was conducted under fully reversed tension-compression loading in lab air at $20^{\circ} \mathrm{C}$ and $250{ }^{\circ} \mathrm{C}$. Specimens were heated in an electric-resistance furnace during conventional-fatigue testing at $250{ }^{\circ} \mathrm{C}$.

\section{Fatigue-Crack Growth}

Fatigue-crack growth studies were performed at 20 and $30 \mathrm{~Hz}$. The gage section of the specimens for crack-growth tests had two additional flats machined onto them (Figure 2). This geometry provides a discrete plane of minimum cross section to facilitate laser machining of notches and optical microscopy observation. The elastic- stress concentration factor due to the flats is approximated from Peterson's handbook ${ }^{[22]}$ to be $K_{t} \approx 1.04$. One flat on each specimen was hand polished using diamond paste to a finish of $1 \mu \mathrm{m}$. A micronotch was machined in the center of the polished flat by using a femtosecond laser beam, which introduces minimal damage to the material around the notch. ${ }^{[23]}$ Figure 4 shows an example of the laser-machined micronotch, from which fatigue cracks nucleated and grew essentially normal to the applied loading direction.

A stress amplitude of 95 and $80 \mathrm{MPa}$ was applied for $20{ }^{\circ} \mathrm{C}$ and $250{ }^{\circ} \mathrm{C}$, respectively. Cracks were observed with the aid of a QUESTAR* telescope mounted on the PA.

*QUESTAR is a trademark of Questar Corporation, New Hope,

test frame. Crack-length measurement was done by acquiring digital images using National Instruments IMAQ**

**IMAQ is a trademark of National Instruments Corporation, Austin, TX.

Vision Builder software and processing the images using ADOBE PHOTOSHOP ${ }^{\dagger}$ software. The resolution of the

${ }^{\dagger}$ ADOBE PHOTOSHOP is a trademark of Adobe Systems Incorporated, San Jose, CA.

crack-length measurement was close to $1 \mu \mathrm{m}$. The crack length projected in the pure-mode I plane was used for analysis.

The cyclic crack-growth rate, $d a / d N$, was determined from the crack length $v s$ number of cycles using a threepoint sliding polynomial method described in ASTM E647. The stress-intensity factor range, $\Delta K$, corresponding to a given crack length was calculated using a solution presented by Newman and Raju ${ }^{[24]}$ for a surface crack growing in a finite plate. Only the tensile portion of the applied stress range was used to calculate $\Delta K$.

This study is intended to ascertain the growth rates of small fatigue cracks, indicative of those initiating at pores. The experimental setup used to optically monitor and digitally record crack growth, coupled with the absence of an initiation lifetime, allowed detection of crack growth directly from the notch. Therefore, no precracking was necessary. However, calculations of crack-growth rates were only made when crack lengths exceeded 20 pct of the notch length to avoid artifacts from the stress-concentration field of the notch.

\section{Environmental Control}

Ultrasonic-fatigue specimens were tested at room temperature in various environments, i.e., ambient air with relative humidity $(\mathrm{RH})$ of approximately 20 to 90 pct, distilled water, and dry air (approximate RH of 0.1 to $0.2 \mathrm{pct}$ ).

Dry air was generated by cooling the air using liquid nitrogen to temperatures below $-50{ }^{\circ} \mathrm{C}$ where the water vapor condensed, reducing water-vapor partial pressure to below $5 \mathrm{~Pa}$. The water-vapor partial pressure in the dry air was measured by a hygrometer, which can continuously monitor water-vapor partial pressure from 0.05 to $100 \mathrm{~Pa}$. The dry air was subsequently pumped into the specimen chamber, which was attached to the load train at vibration nodes to avoid damping the vibration. 


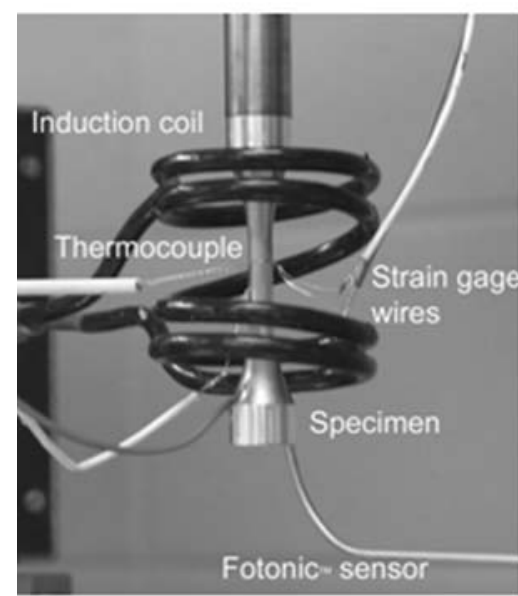

(a)

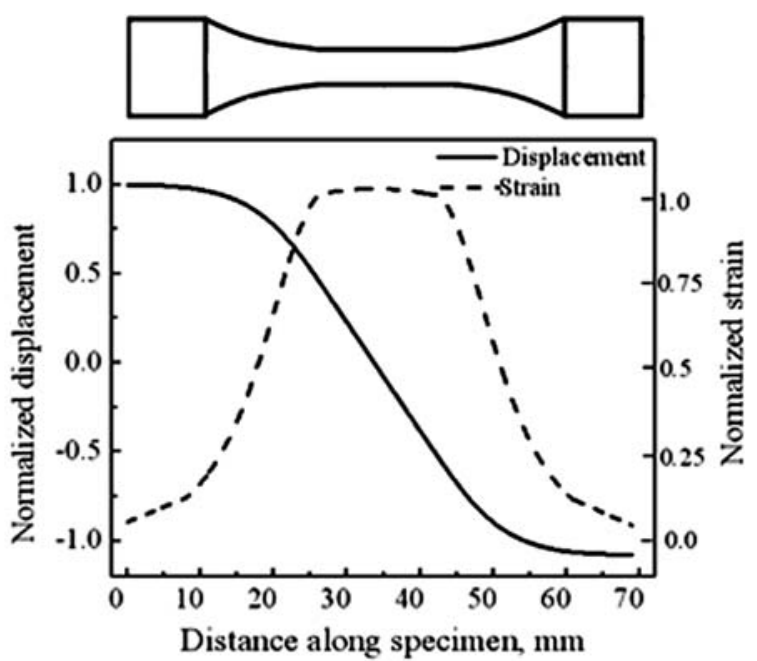

(b)

Fig. 3-(a) Specimen fixtured for ultrasonic-fatigue testing with strain measurement, displacement measurement, and induction-heating arrangement; and $(b)$ distribution of displacement and strain along the specimen.

To facilitate optical observation of crack growth, the specimen chamber was equipped with a flat window.

\section{RESULTS AND DISCUSSION}

\section{A. Effect of Frequency and Environment on Fatigue-Crack Propagation at $20^{\circ} \mathrm{C}$}

In ambient air, the fatigue-crack growth rate of E319 cast-aluminum alloy was increased by decreasing the testing frequency (Figure 5). The crack-propagation curves at $20 \mathrm{kHz}, 30 \mathrm{~Hz}$, and $1 \mathrm{~Hz}$ are essentially parallel within the examined stress-intensity range (1 to $4 \mathrm{MPa} \sqrt{\mathrm{m}}$ ). The crack-growth rates for 30 and $1 \mathrm{~Hz}$ are very similar and are approximately 5 times greater than that at $20 \mathrm{kHz}$ at an equivalent stressintensity factor range. The crack-growth rate at $1 \mathrm{~Hz}$ is slightly lower than the crack-growth rate at $30 \mathrm{~Hz}$, which might be caused by the scatter of crack-growth rate from specimen to specimen. At $30 \mathrm{~Hz}$, the initial deceleration of crack-growth rates is believed to arise from small crack-growth behavior.

At $20 \mathrm{kHz}$, crack-growth rate was also increased by increasing the water content in the environment (Figure 6). The crack-propagation curves for dry air and ambient air are essentially parallel, and the crackgrowth rates in ambient air are approximately 10 times higher than the crack-growth rates in dry air. The crackgrowth curve for distilled water has a lower slope. The crack-growth rates in water are more than 10 times higher than the crack-growth rates in ambient air at low stress-intensity levels, and the difference in crack-growth rates becomes smaller at high stress-intensity levels.

From Figures 5 and 6, it is expected that high watervapor pressure and low-cyclic frequency have similar effects on crack-growth rates. The combined effect of frequency and environment on fatigue-crack growth rate can be expressed in terms of water exposure, $P / f$.
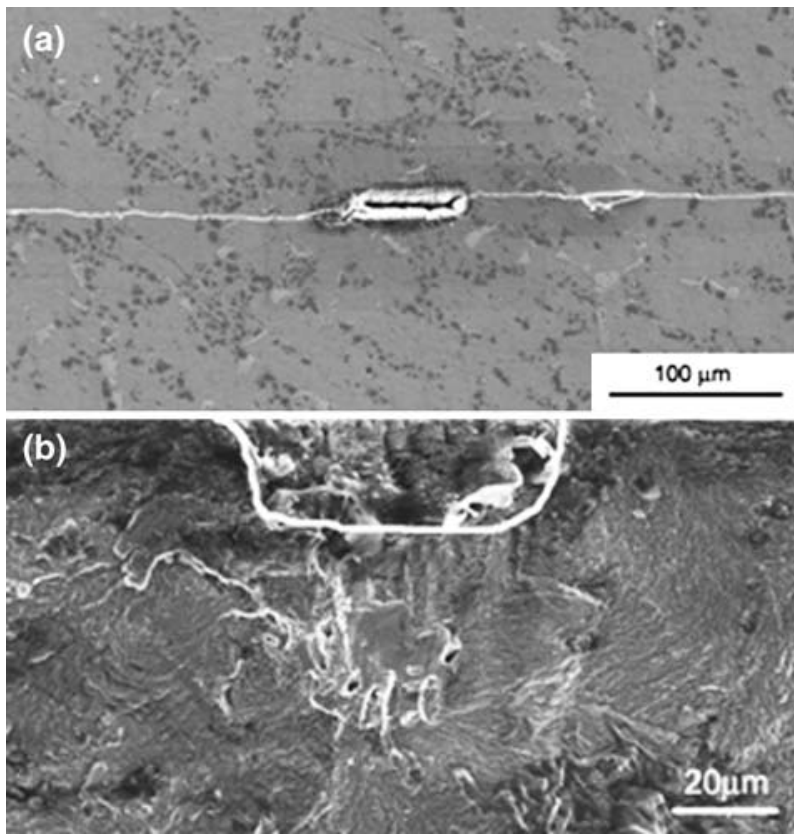

Fig. 4 - (a) Montage of SEM images showing a fatigue-crack propagating from a laser-machined micronotch and $(b)$ normal view the fatigue-fracture surface with the micronotch highlighted.

Here, $P$ is the water partial pressure, and $f$ is the cyclic frequency. The dependence of crack-growth rate of E319 at constant $\Delta K$ of $2 \mathrm{MPa} \sqrt{\mathrm{m}}$ on water exposure is shown in Figure 7. It can be seen that crack-growth rates increase with water exposure and then become essentially independent of water exposure, indicating a saturated environmental effect. Similar dependence of crack-growth rate on water exposure was observed for a $7075-\mathrm{T} 651$ aluminum alloy ${ }^{[15]}$ and some $\mathrm{Al}-\mathrm{Cu}-\mathrm{Mg} / \mathrm{Li}$ alloys. ${ }^{[25]}$ 


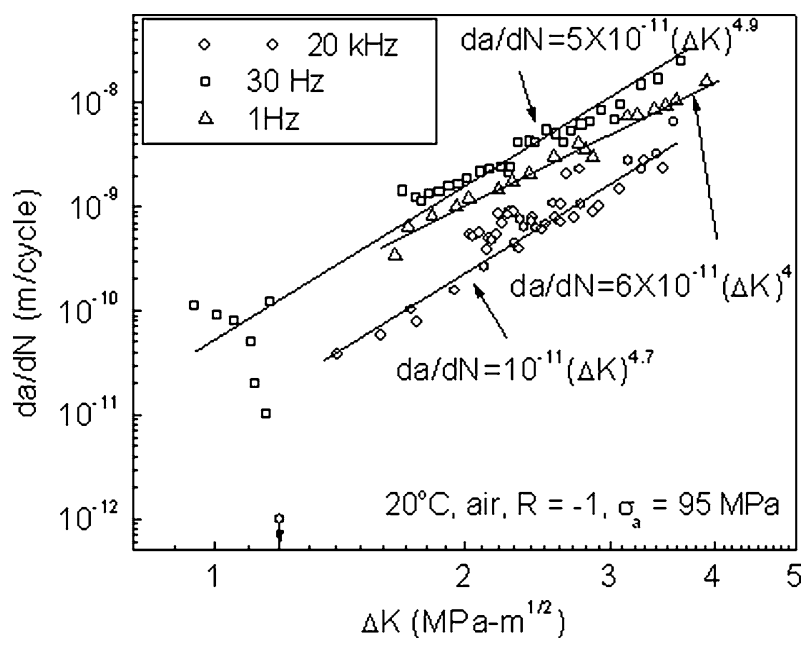

Fig. 5-Fatigue-crack propagation of E319 cast-aluminum alloy at $20 \mathrm{kHz}, 30 \mathrm{~Hz}$, and $1 \mathrm{~Hz}$ in ambient air.

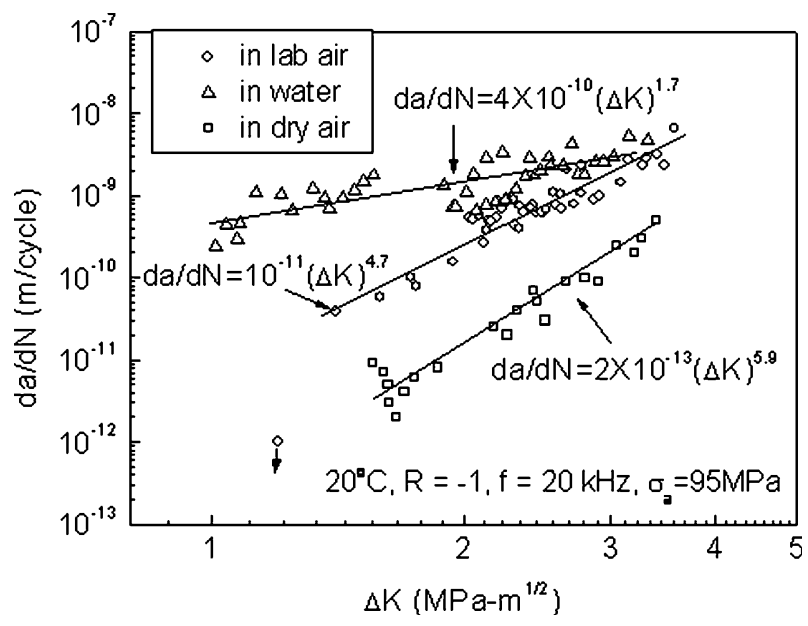

Fig. 6-Fatigue-crack propagation of E319 cast-aluminum alloy in ambient air, distilled water, and dry air at $20 \mathrm{kHz}$.

The calculated water exposure in each environmental condition is summarized in Table II. Here, the water partial pressure, $P$, was calculated as follows:

$$
P=P_{s} \times R H
$$

where $P_{S}$ is the saturation water partial pressure in ambient air $\left(P_{S}=2338 \mathrm{~Pa}\right)$, and $R H$ is the relative humidity. The relative humidity in laboratory air is measured to be approximately 40 pct. In this study, the pressure of liquid water was assumed to be $10^{5} \mathrm{~Pa}$. However, it should be pointed out that there is no agreement in the literature regarding this value during fatigue testing; the actual water pressure around the fatigue-crack during cyclic loading could be less than $10^{5} \mathrm{~Pa}$. The water-vapor pressure in dry air was controlled below $5 \mathrm{~Pa}$.

Fractographic examination of the fatigue specimens in environments with different water exposure at room temperature was performed using scanning electron microscopy (SEM). Surprisingly, although the crack-

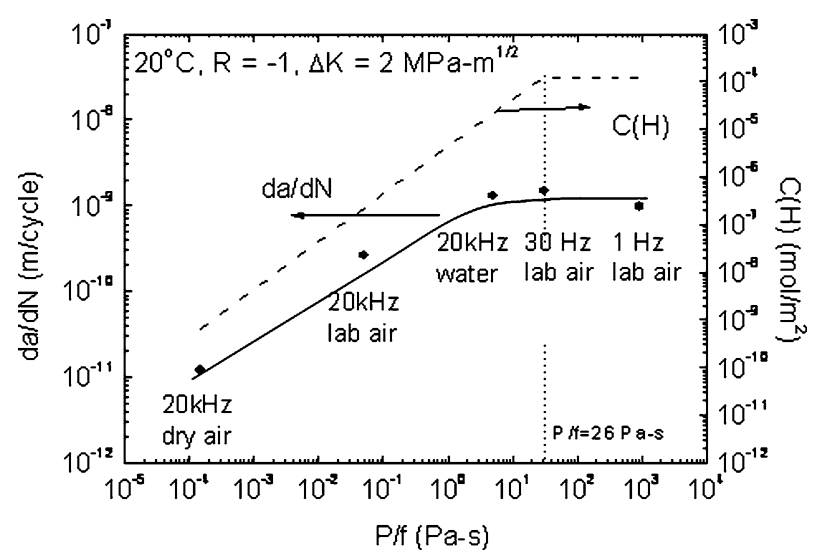

Fig. 7-Dependence of crack growth and estimated hydrogen concentration on water exposure of E319 cast-aluminum alloy at $20{ }^{\circ} \mathrm{C}$.

Table II. Calculated Water Exposure in Various Environments

\begin{tabular}{llcl}
\hline & $f(\mathrm{~Hz})$ & $P(\mathrm{~Pa})$ & $P / f(\mathrm{~Pa} \mathrm{~s})$ \\
\hline Dry air & 20,000 & 5 & $2.5 \times 10^{-4}$ \\
Lab air & 20,000 & 935 & 0.05 \\
Water & 20,000 & $10^{5}$ & 5 \\
Lab air & 30 & 935 & 31 \\
Lab air & 1 & 935 & 935 \\
\hline
\end{tabular}

growth rates were observed to be influenced by water exposure, the fatigue-fracture surfaces do not exhibit obvious differences in morphology for the various environments. The typical fatigue-fracture surfaces at $\Delta K$ of approximately $2.5 \mathrm{MPa} \sqrt{\mathrm{m}}$ are shown in Figure 8. Figures 8(a) and (b) represent the fracture surface at $20 \mathrm{kHz}$ in dry air (very low water exposure), and Figures $8(\mathrm{c})$ and $(\mathrm{d})$ represent the fracture surface at $1 \mathrm{~Hz}$ in ambient air (high water exposure with saturated environmental effect). In all cases, the fracture surfaces are generally normal to the loading direction. The features typical of transgranular crack growth that were reported for some aluminum alloys ${ }^{[25]}$ were not observed. This is consistent with the observations that fatigue-crack growth in overaged aluminum alloys favors a wavy slip mode and exhibits conventional stage II propagation. ${ }^{[26]}$ In general, the peak-aged aluminum matrix contains shearable GP zones and the precipitates, which promote a localization of the plastic deformation within a single-slip system in each individual grain along the crack front and favor a near-threshold crystallographic crack path. The overaged aluminum matrix contains larger and less coherent precipitates, which favor a wavy slip mechanism. At low magnification, the fracture surfaces are characterized by a large number of transgranular facets and "riverlines." At high magnification, striation-like features are observable. These striation-like features look finer for the case of fatiguecrack growth with small environmental effect Figure 8(b)) than those for the case of fatigue-crack growth with significant environmental effect (Figure 8(d)). 

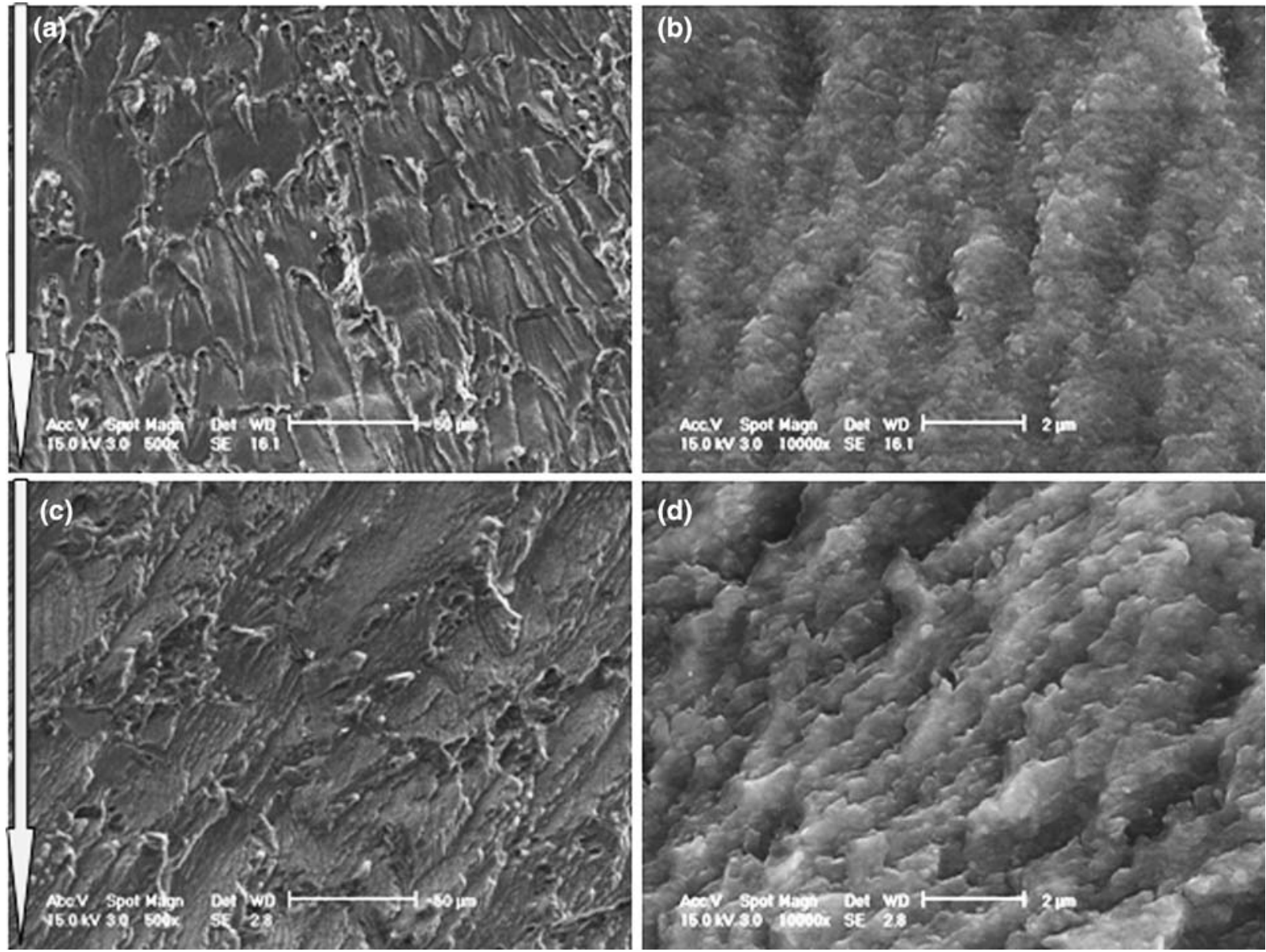

Fig. 8-Fracture surface in environments at $\Delta K=2.5 \mathrm{MPa} \sqrt{\mathrm{m}}$; crack-growth direction is from top to bottom, as indicated by the arrow. (a) $20 \mathrm{kHz}$, in dry air, low magnification; (b) $20 \mathrm{kHz}$, in dry air, high magnification; (c) $1 \mathrm{~Hz}$, in ambient air, low magnification; and (d) $1 \mathrm{~Hz}$, in ambient air, high magnification.

Three possible mechanisms for hydrogen-assisted cracking have been proposed:[27] hydrogen-enhanced decohesion, adsorption-induced dislocation emission, and hydrogen-enhanced localized plasticity. However, in the current study, it was not possible to determine which mechanism is operative based on the fracturesurface morphologies. The subtle change of fracturesurface morphology with water exposures indicates that, although the fatigue-propagation behavior is influenced by water exposure, the response of fatigue-crack growth rate to the water exposure for the investigated E319-T7 cast-aluminum alloy is not as significant as for those aluminum alloys, which exhibited obvious morphology change of fracture surface in different environments. ${ }^{\text {[25] }}$

\section{B. Effect of Frequency and Temperature on Fatigue-Crack Propagation at $250{ }^{\circ} \mathrm{C}$}

Figure 9 presents the fatigue-crack propagation at $20{ }^{\circ} \mathrm{C}$ and $250{ }^{\circ} \mathrm{C}$, at a frequency of $20 \mathrm{kHz}$. In the investigated stress-intensity range (1 to $4 \mathrm{MPa} \sqrt{\mathrm{m}})$, a substantial increase of crack-growth rates results from the increase of temperature. At equivalent stressintensity levels, the crack-growth rate at $250{ }^{\circ} \mathrm{C}$ is approximately 10 times greater than the crack-growth rate at room temperature.

When the stress-intensity factor range is normalized by Young's modulus and yield strength, the fatiguecrack growth rates at $250{ }^{\circ} \mathrm{C}$ become close to those at $20{ }^{\circ} \mathrm{C}$, as shown in Figure 10 . This suggests that the difference of crack-growth rates between $20^{\circ} \mathrm{C}$ and $250{ }^{\circ} \mathrm{C}$ in air primarily results from the change of their mechanical properties with temperature. For this cast-aluminum alloy, it was also determined that normalization of the stress-intensity factor range only by Young's modulus is not sufficient to make the crack-growth rates at $20{ }^{\circ} \mathrm{C}$ and $250{ }^{\circ} \mathrm{C}$ fall in the same data band, indicating that Young's modulus is not the only factor influencing the temperature effect on crack-growth rates. After normalization of the stress-intensity factor range, the crack-growth rates at $250{ }^{\circ} \mathrm{C}$ in air are slightly lower than those at $20^{\circ} \mathrm{C}$, indicating that effect of environment on fatigue-crack growth rates operates slightly differently for $20^{\circ} \mathrm{C}$ and $250{ }^{\circ} \mathrm{C}$, but environment clearly is not a significant accelerating factor at least at $20 \mathrm{kHz}$. The effect of environment at elevated temperature is discussed further in Section D. 


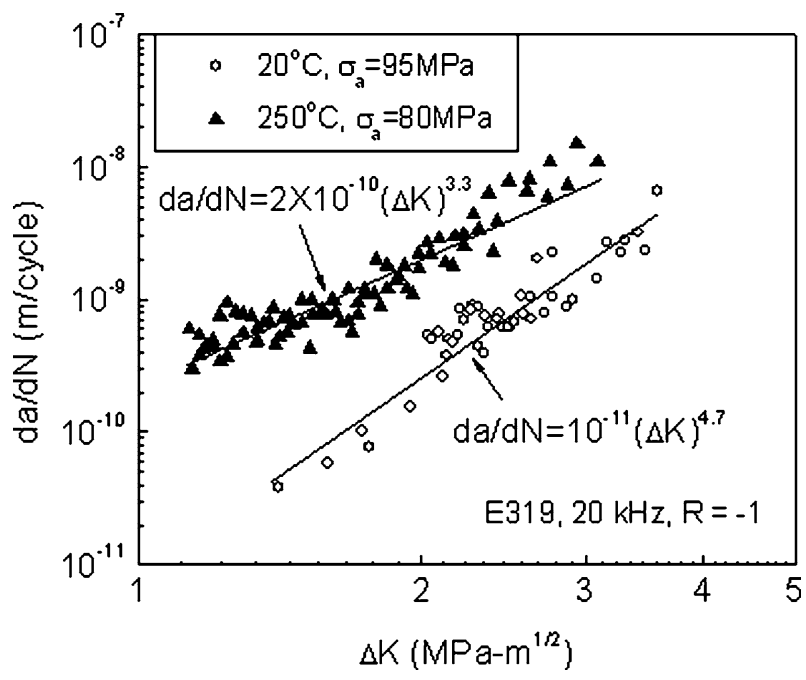

Fig. 9- Small fatigue-crack propagation in E319 cast-aluminum alloy at $20^{\circ} \mathrm{C}$ and $250{ }^{\circ} \mathrm{C}$, at testing frequency of $20 \mathrm{kHz}$ and under fully reversed loading condition $(R=-1)$.

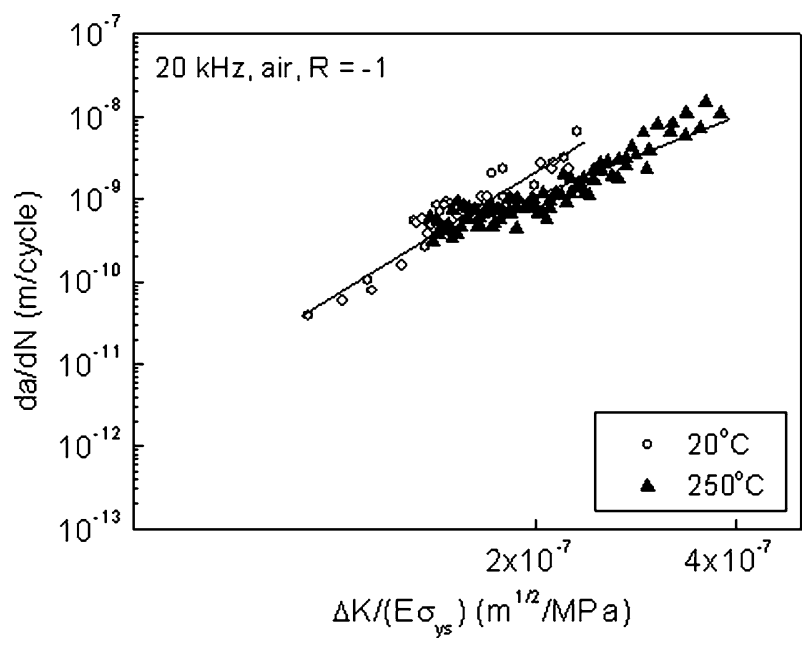

Fig. 10-Fatigue-crack propagation in E319 cast-aluminum alloy at $20{ }^{\circ} \mathrm{C}$ and $250{ }^{\circ} \mathrm{C}$ characterized by normalized stress-intensity factor range $\left(\Delta K /\left(E \sigma_{y s}\right)\right)$.

To examine the effect of frequency on fatigue propagation at elevated temperature, the crack-growth rates in air at $20 \mathrm{kHz}$ and $30 \mathrm{~Hz}$ at $250{ }^{\circ} \mathrm{C}$ are compared, as shown in Figure 11. It can be seen at $250{ }^{\circ} \mathrm{C}$ that the fatigue-crack growth rate at $30 \mathrm{~Hz}$ is approximately 2 to 5 times greater than that at $20 \mathrm{kHz}$ at an equivalent level of stress intensity. This is compared well to an order of magnitude effect of frequency at room temperature (Figure 5). Similar to the scenario at room temperature, the observed effect of frequency is still attributable to an environmental effect. At elevated temperature, another possible time-dependant deformation mechanism is creep. However, for E319 cast-aluminum alloy, the fatigue-crack growth rates at elevated temperature do not appear to be influenced by creep-fatigue interaction. At $250^{\circ} \mathrm{C}$, the

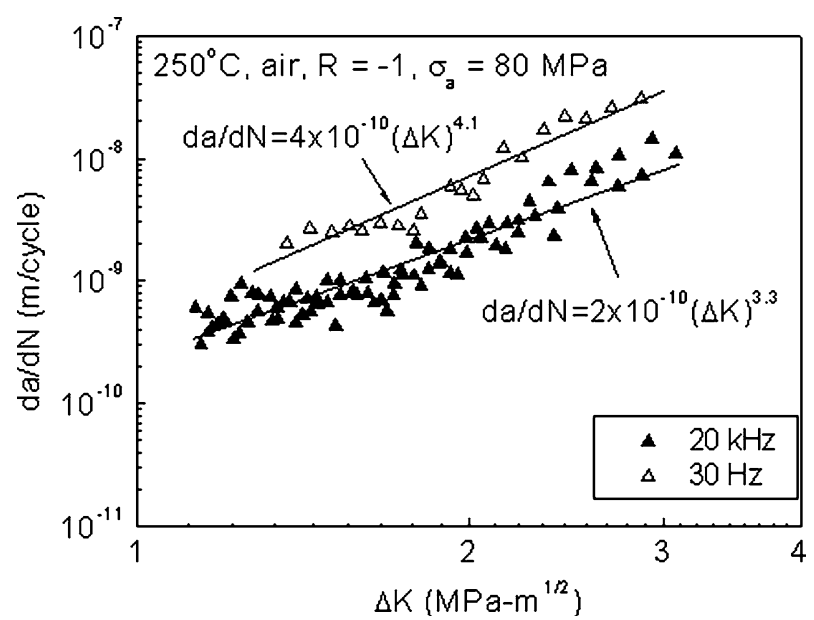

Fig. 11-Fatigue-crack propagation in E319 cast-aluminum alloys tested at $20 \mathrm{kHz}$ and $30 \mathrm{~Hz}$ at $250{ }^{\circ} \mathrm{C}$ in laboratory air $(R=-1$, $\left.\sigma_{a}=80 \mathrm{MPa}\right)$

creep strain rate is on the order of $10^{-8}$ per second at stress levels of 60 to $80 \mathrm{MPa}{ }^{[28]}$ As such, strain caused by creep during each cycle is approximately $10^{-10}$ at conventional frequency and $10^{-13}$ at ultrasonic frequency. These values are far below the fatigue-strain amplitude, which is on the order of $10^{-3}$. Since the strain caused by creep at $250{ }^{\circ} \mathrm{C}$ is negligible compared to the strain caused by cyclic loading, it is reasonably assumed that the fatigue-crack growth rate is not influenced by creep.

\section{Mechanisms and Modeling of Environmental Effect on Fatigue-Crack Propagation}

In the model proposed by Wei et al.,$^{[15,29]}$ the processes for the increase of fatigue-crack growth rates in the presence of water vapor are described in three steps: first, water molecules migrate to the crack tip by impeded molecular transport, i.e., Kundsen flow; ${ }^{[30]}$ second, water reacts with aluminum on the freshly formed fatigue-crack surface and hydrogen atoms form from the dissociation reaction (Eq. [3]); third, hydrogen atoms diffuse from the crack surface to the crack-tip plastic zone, causing hydrogen-assisted cracking as follows:

$$
2 \mathrm{Al}+4 \mathrm{H}_{2} \mathrm{O} \rightarrow \mathrm{Al}_{2} \mathrm{O}_{3} \cdot \mathrm{H}_{2} \mathrm{O}+6 \mathrm{H}
$$

These three steps operate in sequence, and the crackgrowth response is governed by the slowest process in the sequence. To determine the rate-limiting step, the time needed for each step can be roughly estimated as follows.

Assume that the water-vapor partial pressure in ambient air is $935 \mathrm{~Pa}$ (equivalent to 40 pct $\mathrm{RH}$ ), and a stress amplitude of $95 \mathrm{MPa}$ is applied to an E319 castaluminum specimen with a small surface crack $(a=300 \mu \mathrm{m})$. The time, $t_{1}$, needed for $10^{-11} \mathrm{~mol}$ water-vapor molecules to migrate to the crack tip by Knudsen flow ${ }^{[30]}$ can be estimated as follows: 


$$
t_{1}=\frac{N}{J A}=\frac{N}{\frac{P}{\sqrt{2 \pi M \mathrm{R} T}} 2 a \frac{4 \sigma a}{E}}=5 \times 10^{-3} \mathrm{~s}
$$

where $N$ is the amount of water-vapor molecules $\left(10^{-11} \mathrm{~mol}\right), J$ is the flux of water molecules through a fatigue crack, $A$ is the area of the crack opening, $P$ is the water-vapor partial pressure, $M$ is the molecular weight of water, $\mathrm{R}$ is the gas constant, $T$ is temperature, $a$ is half crack length, $\sigma$ is stress amplitude, and $E$ is the Young's modulus.

The time, $t_{2}$, needed for $10^{-11} \mathrm{~mol}$ water-vapor molecules to react with the fresh fracture surface can be estimated by assuming a first order reaction as follows:

$$
t_{2}=-\frac{1}{4 k_{c}}\left(\ln N_{f}-\ln N_{0}\right)=6 \times 10^{-4} \mathrm{~s}
$$

where $k_{c}$ is the reaction-rate constant for water-aluminum reaction (of the order $10^{3} \mathrm{~s}^{-1}$ ), ${ }^{[31]} N_{f}$ is the amount of the remaining water-vapor molecules (assuming $N_{f}=$ $10^{-12} \mathrm{~mol}$ ), and $N_{0}$ is the original amount of the watervapor molecules $\left(10^{-11} \mathrm{~mol}\right)$.

The time, $t_{3}$, needed for hydrogen atoms to diffuse to plastic zone can be estimated by assuming that the hydrogen-concentration profile ahead of the crack tip can be modeled by a steady-state diffusion in a semiinfinite body with a fixed concentration source and that if the distance of diffusion exceeds the nominal crack extension per cycle, hydrogen-assisted increase of crackgrowth rate will occur as follows: ${ }^{[32,33]}$

$$
t_{3}=\frac{1}{D}\left(\frac{d a / d N}{4}\right)^{2}=5 \times 10^{-6} \mathrm{~s}
$$

where $D$ is the diffusion coefficient $\left(1.19 \times 10^{-14}\right.$ $\mathrm{m}^{2} / \mathrm{s}^{[34]}$ ), and $d a / d N$ is the crack-growth rate (assuming $d a / d N=10^{-9} \mathrm{~m} / \mathrm{s}$ ).

By comparing $t_{1}, t_{2}$, and $t_{3}$, it can be seen that the time for migration of water molecules to crack tip is much longer than that for either surface reaction or hydrogen diffusion. Therefore, migration of water molecules is the rate-limiting step. This is consistent with the results by Wei et al., ${ }^{[15,29]}$ i.e., for highly reactive gas-metal systems, such as water vapor and aluminum, hydrogenassisted fatigue-crack growth is controlled by the rate of transport of water molecules to the crack tip.

The environmental contribution to the fatigue-crack growth rate is assumed to be determined by the concentration of hydrogen atoms at the crack tip produced in each loading cycle. The hydrogen concentration can be considered as a bridge that connects the influence of water on surface reaction kinetics and the resultant crack-growth performance. However, the concentration of hydrogen is controlled not by hydrogen diffusion or the fracture-surface reaction but by transport of water to the crack tip. To quantify the concentration of hydrogen, the concentration of water available on the fresh fracture surface has to be determined, and this value is limited by Knudsen flow ${ }^{[30]}$ of water vapor from the surrounding environment to the crack tip.

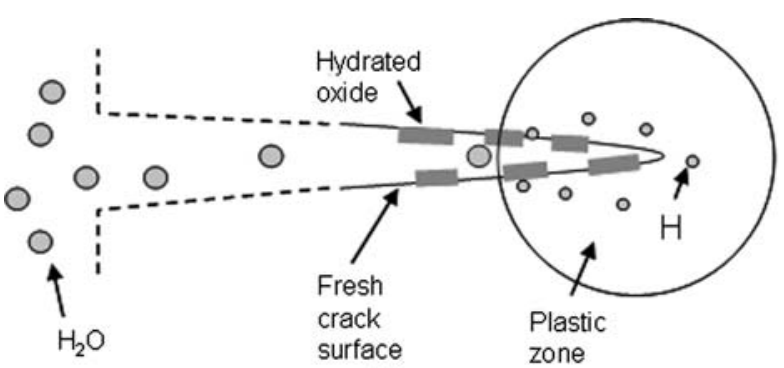

(a)

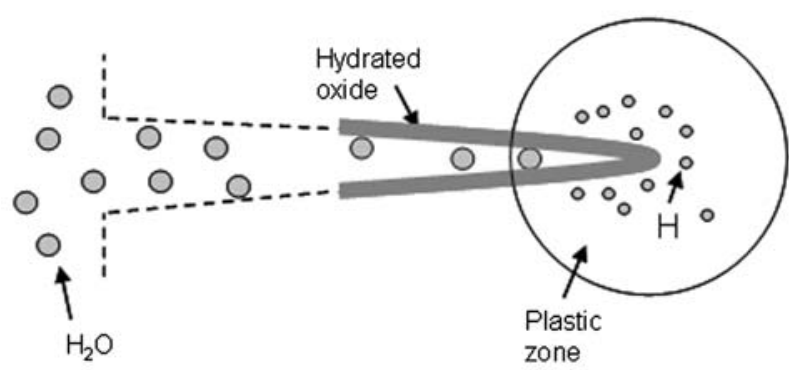

(b)

Fig. 12-Schematic of the mechanisms of the crack-tip surface reaction with water vapor forming a hydrated oxide and hydrogen atoms: (a) partially surface coverage and $(b)$ saturated surface coverage.

By assuming Knudsen flow, ${ }^{[30]}$ the average concentration of water vapor $\left(C_{\mathrm{H}_{2} \mathrm{O}}\right.$, in $\left.\mathrm{mol} / \mathrm{m}^{2}\right)$ on the fresh fracture surface of a semicircular crack can be estimated as follows: ${ }^{[17]}$

$$
C_{\mathrm{H}_{2} \mathrm{O}}=\frac{4 \sigma_{\max }}{E \sqrt{2 \pi^{3} M \mathrm{RT}}} \frac{P}{f}
$$

where $\sigma_{\max }$ is the maximum stress $(\mathrm{MPa}), E$ is the Young's modulus (MPa), $M$ is the molecular mass of water vapor $(\mathrm{g} / \mathrm{mol}), \mathrm{R}$ is the universal gas constant $(8.314 \mathrm{~J} / \mathrm{mol} / \mathrm{K}), T$ is the temperature $(\mathrm{K}), P$ is the water-vapor partial pressure $(\mathrm{Pa})$, and $f$ is the loading frequency $(\mathrm{Hz})$.

The concentration of hydrogen is proportional to the concentration of water and can be described as follows:

$$
C_{\mathrm{H}}=\frac{3}{2} C_{\mathrm{H}_{2} \mathrm{O}}=\frac{6 \sigma_{\max }}{E \sqrt{2 \pi^{3} M \mathrm{RT} T}} \frac{P}{f}
$$

It should be pointed out that when the entire fresh fracture surface has been reacted with water and a monolayer of hydrated oxide has formed, the maximum possible concentration of hydrogen is reached, and the environmental effect becomes saturated, as shown schematically in Figure 12(b). Assuming that when saturation occurs, a monolayer of atoms in the aluminum lattice has been reacted with water, and the surface concentration of aluminum can be estimated to be $4 \times 10^{-5} \mathrm{~mol} / \mathrm{m}^{2}$ based on the following equation:

$$
C_{\mathrm{Al}}=\frac{d \rho_{\mathrm{Al}}}{M_{\mathrm{Al}}}
$$




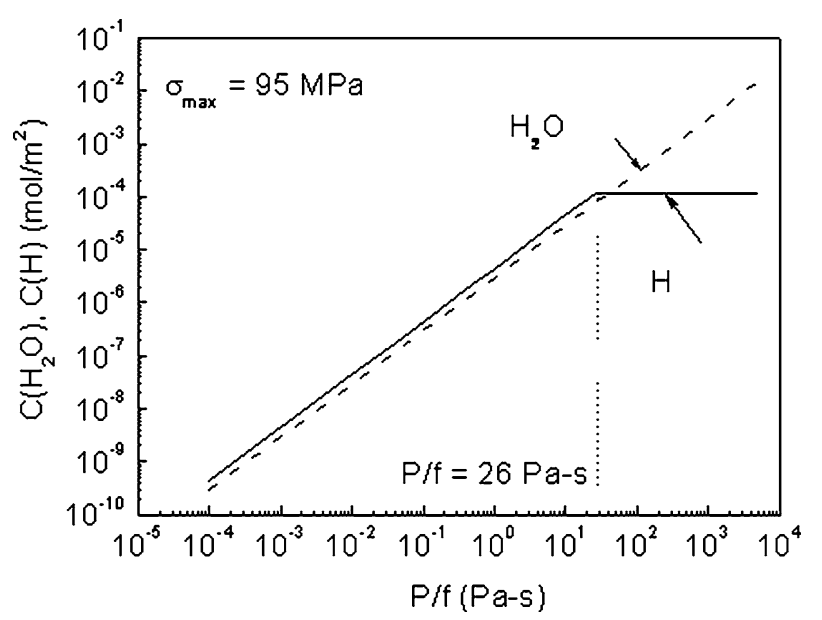

Fig. 13-Estimated concentration of water vapor and hydrogen on the fresh fracture surface as a function of water exposure.

where $d$ is the lattice constant of aluminum $\left(4 \times 10^{-10} \mathrm{~m}\right), \quad \rho_{\mathrm{Al}}$ is the density of aluminum $\left(2.7 \times 10^{6} \mathrm{~g} / \mathrm{m}^{3}\right)$, and $M_{\mathrm{Al}}$ is the atomic weight of aluminum $(27 \mathrm{~g} / \mathrm{mol})$. According to Eq. [3], the concentration of hydrogen at saturation is proportionally estimated to be $1.2 \times 10^{-4} \mathrm{~mol} / \mathrm{m}^{2}$. Thus, the critical water exposure when saturation of hydrogen concentration occurs can be estimated as follows:

$$
\left(\frac{P}{f}\right)_{s}=1.9 \times 10^{-3} \sqrt{T} \frac{E}{\sigma_{\max }}
$$

at room temperature, and a stress amplitude of $95 \mathrm{MPa}$; $(P / f)_{S}$ is estimated to be $26 \mathrm{~Pa}$ s for the water-aluminum system.

The estimated concentrations of water vapor and hydrogen are plotted as a function of water exposure in Figure 13. It is shown that the concentration of water and hydrogen increases with water exposure until $P / f=26 \mathrm{~Pa}$ s. Above $P / f=26 \mathrm{~Pa} \mathrm{~s}$, although the concentration of water still increases with water exposure, the concentration of hydrogen remains at the maximum value, which corresponds to a saturation of environmental effect when the entire fresh fracture surface has been reacted with water, and a monolayer of hydrated oxide has been formed.

Interestingly, the dependence of fatigue-crack growth rate on water exposure closely follows the assumed dependence of hydrogen concentration on water exposure, as shown in Figure 7. The observed saturated environmental effect on crack-growth rate and the estimated saturated concentration of hydrogen occur at approximately the same water exposure $(P / f=26 \mathrm{~Pa} \mathrm{~s})$. This correlation strongly supports the assumption that the increase in crack-growth rate caused by environment is determined by the concentration of hydrogen at the crack tip. Thus, $(P / f)_{S}$ is termed the saturation water exposure, above which hydrogen concentration at the crack tip and fatigue-crack growth rate are independent of $P / f$.

Wei et al. ${ }^{[15,29]}$ proposed the following superposition model to quantify the effect of water exposure on the fatigue-crack growth rate:

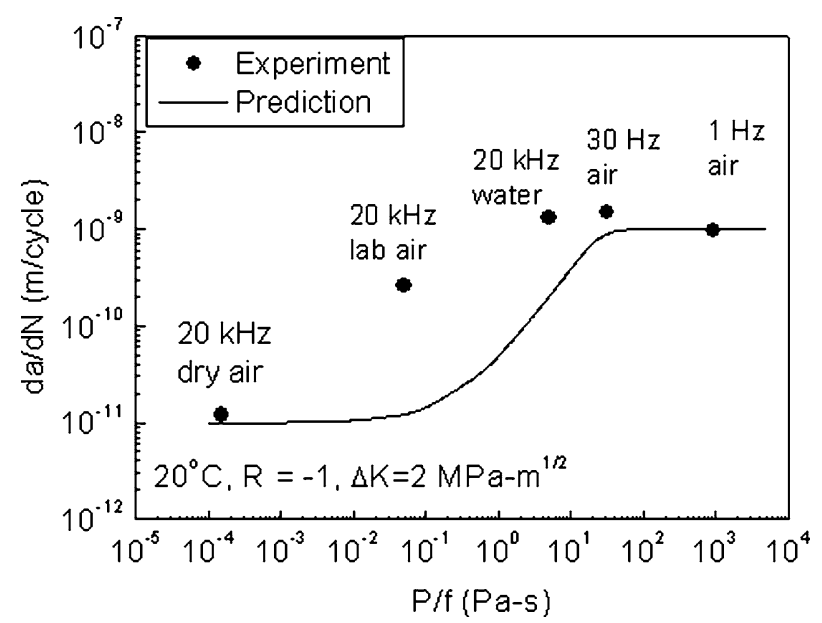

Fig. 14-Predicted fatigue-crack growth response as a function of water exposure based on the superposition model (Eqs. [11] through [13]), compared with experimental data, at a constant $\Delta K$ of $2 \mathrm{MPa} \sqrt{\mathrm{m}}$.

$$
\begin{aligned}
& \text { For }\left(\frac{P}{f}\right)<\left(\frac{P}{f}\right)_{s}: \\
& \qquad\left(\frac{d a}{d N}\right)_{\mathrm{tot}}=\left(\frac{d a}{d N}\right)_{\mathrm{mech}}+\left(\frac{d a}{d N}\right)_{\mathrm{env}} \\
& \left(\frac{d a}{d N}\right)_{\mathrm{env}}=\left[\left(\frac{d a}{d N}\right)_{\mathrm{sat}}-\left(\frac{d a}{d N}\right)_{\mathrm{mech}}\right] \frac{(P / f)}{(P / f)_{s}} \\
& \text { For }\left(\frac{P}{f}\right) \geq\left(\frac{P}{f}\right)_{s}:\left(\frac{d a}{d N}\right)_{\mathrm{tot}}=\left(\frac{d a}{d N}\right)_{\mathrm{sat}}
\end{aligned}
$$

Here, $(d a / d N)_{\text {tot }}$ is the fatigue-crack growth rate in a deleterious environment and can be described as the sum of two independent components, $(d a / d N)_{\text {mech }}$ and $(d a / d N)_{\mathrm{env}}(d a / d N)_{\text {mech }}$ is the fatigue-crack growth rate in an inert environment (called pure-mechanical fatiguecrack growth rate); $(d a / d N)_{\mathrm{env}}$ is the environmental contribution to the fatigue-crack growth rate (called environmental fatigue-crack growth rate). When the environmental effect becomes saturated, $(d a / d N)_{\text {tot }}$ reaches the maximum value, $(d a / d N)_{\text {sat }}$ (saturated fatigue-crack growth rate). The environmental fatiguecrack growth rate is determined by $(d a / d N)_{\text {mech }}$, $(d a / d N)_{\text {sat }}, P / f$, and $(P / f)_{s}$. The values of $(d a / d N)_{\text {mech }}$ and $(d a / d N)_{\text {sat }}$ can be estimated based on the experimental observations in Figure 7 . At a constant $\Delta K$ of $2 \mathrm{MPa} \sqrt{\mathrm{m}},(d a / d N)_{\text {mech }}$ was assumed to be $10^{-11}$ $\mathrm{m} /$ cycle, which is equivalent to the crack-growth rate in dry air at $20 \mathrm{kHz}$, where the environmental effect is very small and the crack growth can be reasonably considered as "pure-mechanical." $(d a / d N)_{\text {sat }}$ was assumed to be $10^{-9} \mathrm{~m} /$ cycle, which is the average fatigue-crack growth rate in ambient air at 30 and $1 \mathrm{~Hz}$ where the environmental effect is saturated.

The predicted dependence of crack-growth rate on water exposure based on the superposition model 
(Eqs. [11] through [13]), with $(d a / d N)_{\text {mech }}=10^{-11}$ $\mathrm{m} /$ cycle and $(d a / d N)_{\text {sat }}=10^{-9} \mathrm{~m} /$ cycle is shown in Figure 14. The predicted crack-propagation curve exhibits a strong curvature at water exposure of $10^{-1} \mathrm{~Pa} \mathrm{~s}$; below this point, fatigue-crack growth rates are not sensitive to water exposure, and above this point, the fatigue-crack growth rates increase abruptly with increasing water exposure until the environmental effect becomes saturated. However, the experimental results do not show such a sudden change of dependence of fatigue-crack growth rate on water exposure. The prediction, therefore, does not agree well with the experimental observations. One possible reason is that in the superposition model, $(d a / d N)_{\mathrm{env}}$ is simply assumed to be linearly related to the concentration of hydrogen, and, therefore, linearly related to water exposure. However, in the present study, $(d a / d N)_{\text {env }}$ was found to be better described by the square root of the hydrogen concentration, as shown in Figure 15. It was also found that the square-root correlation between $(d a / d N)_{\text {env }}$ and $C_{H}$ fits the data better than other simple mathematic relations, i.e., logarithmic, exponential, and polynomial.

The square-root correlation between $(d a / d N)_{\mathrm{env}}$ and $C_{H}$ suggests that the response of fatigue-crack growth rate in E319-T7 cast-aluminum alloy to water exposure is less significant than presumed in the superposition model, which has successfully modeled fatigue-crack growth rate for some peak-aged (T6) aluminum alloys. ${ }^{[15,29]}$ In other words, the role of hydrogen concentration in increasing of fatigue-crack growth rates might be different for $\mathrm{T} 7$ and $\mathrm{T} 6$ heat-treated aluminum alloys. T6 heat treatment promotes localized plastic deformation within a single-slip system in each grain along the crack front, while $\mathrm{T} 7$ heat treatment favors a wavy slip mechanism. ${ }^{[26]}$ In ambient air, the single-slip mechanism, which is operative in the peakaged alloy, is assumed to offer a preferential path for hydrogen-assisted cracking, which leads to a stronger environmental effect. In contrast, in the $\mathrm{T} 7$ heat treatment, local hydrogen concentration would be less deleterious to fatigue cracking, as indicated by the square-root dependence.

As such, for E319-T7, the superposition model was then modified as follows:

$$
\begin{aligned}
\text { For }\left(\frac{P}{f}\right)<\left(\frac{P}{f}\right)_{s}: \\
\begin{aligned}
\left(\frac{d a}{d N}\right)_{\text {tot }}= & \left(\frac{d a}{d N}\right)_{\text {mech }} \\
& +\left[\left(\frac{d a}{d N}\right)_{\text {sat }}-\left(\frac{d a}{d N}\right)_{\text {mech }}\right] \sqrt{\frac{(P / f)}{(P / f)_{s}}}
\end{aligned}
\end{aligned}
$$

$$
\begin{aligned}
& \text { For }\left(\frac{P}{f}\right) \geq\left(\frac{P}{f}\right)_{s} \\
& \qquad\left(\frac{d a}{d N}\right)_{\text {tot }}=\left(\frac{d a}{d N}\right)_{\text {sat }}
\end{aligned}
$$

The predicted crack-growth response at a constant $\Delta K$ of $2 \mathrm{MPa} \sqrt{\mathrm{m}}$ as a function of water exposure based on the modified superposition model is shown in Figure 16. It can be seen that the predicted fatigue- crack propagation curve gradually increases with increasing water exposure, which agrees reasonably well with the experimental results. Although the mechanisms of the square-root correlation are not known yet, for the purpose of studying the environmental effect on fatiguecrack propagation of E319 cast-aluminum alloy, we have assumed the applicability of this modified superposition model as the basis for modeling hydrogenassisted fatigue-crack growth behavior.

At all levels of $\Delta K,(d a / d N)_{\text {mech }}$ and $(d a / d N)_{\text {sat }}$ can be estimated by assuming the Paris law behavior as follows:

$$
\begin{gathered}
(d a / d N)_{\text {mech }}=C_{1}(\Delta K)^{m_{1}} \\
(d a / d N)_{\mathrm{sat}}=C_{2}(\Delta K)^{m_{2}}
\end{gathered}
$$

where $C_{1}$ and $m_{1}$ correspond to the fatigue-crack growth rates in dry air at $20 \mathrm{kHz}\left(C_{1}=2 \times 10^{-13}, m_{1}=5.9\right)$ and $C_{2}$ and $m_{2}$ correspond to the average fatigue-crack growth rates in ambient air at 30 and $1 \mathrm{~Hz}$ $\left(C_{2}=5 \times 10^{-11}, m_{2}=4.5\right)$. By incorporating the Paris law (Eqs. [16] and [17]) and $(P / f)_{s}$ (Eq. [10]) into the modified superposition model, the effect of environment on fatigue-crack growth rates at all levels of stress intensity range, $\Delta K$, can be estimated as follows:

$$
\begin{aligned}
& \text { For }\left(\frac{P}{f}\right)<\left(\frac{P}{f}\right)_{s}: \\
& \begin{aligned}
\left(\frac{d a}{d N}\right)_{\text {tot }}= & C_{1}(\Delta K)^{m_{1}} \\
& +23 \times\left[C_{2}(\Delta K)^{m_{2}}-C_{1}(\Delta K)^{m_{1}}\right] \sqrt{\frac{\sigma_{\max }}{E \sqrt{T}} \frac{P}{f}}[18
\end{aligned} \\
& \text { For }\left(\frac{P}{f}\right) \geq\left(\frac{P}{f}\right)_{s}: \quad\left(\frac{d a}{d N}\right)_{\text {tot }}=C_{2}(\Delta K)^{m_{2}}
\end{aligned}
$$

The predicted environmental effect on crack-growth rates is shown in Figure 17. $(d a / d N)_{\text {mech }}$ represents the fatigue-crack growth rate without environmental effect, and $(d a / d N)_{\text {sat }}$ represents the fatigue-crack growth rate with maximum environmental effect. Therefore, $(d a / d N)_{\text {mech }}$ and $(d a / d N)_{\text {sat }}$ can be considered as the lower bound and upper bound of crack-growth rates in environment. In other words, crack-growth rates under any water exposure would fall in the range from $(d a / d N)_{\text {mech }}$ to $(d a / d N)_{\text {sat }}$. The extent of the environmental effect on crack-growth rate is determined by water exposure, $P / f$, at a given temperature and a given stress. At $20 \mathrm{kHz}$ in ambient air (Figure 17(a)), $(d a / d N)_{\text {tot }}$ is approximately 5 to 10 times greater than $(d a / d N)_{\text {mech }}$, suggesting that environment plays an important role in crack-growth behavior. $(d a / d N)_{\text {tot }}$ is more than 10 times lower than $(d a / d N)_{\text {sat }}$, indicating that the environmental effect is far from saturated for fatigue testing in ambient air at $20 \mathrm{kHz}$. At $30 \mathrm{~Hz}$ in ambient air, (Figure 17(b)), the environmental effect is saturated, and $(d a / d N)_{\text {tot }}$ reaches the upper bound. 


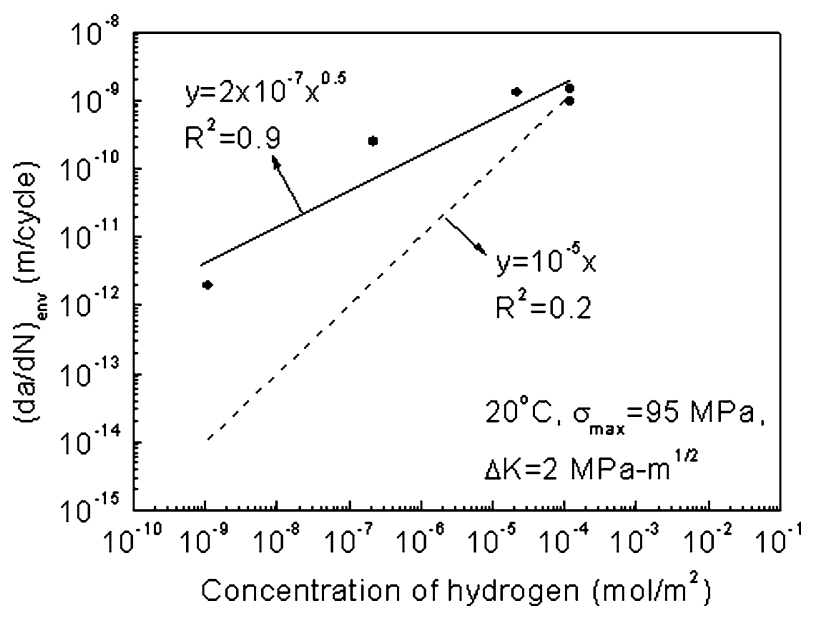

Fig. 15- Correlation of environmental contribution to fatigue-crack growth rate and concentration of hydrogen.

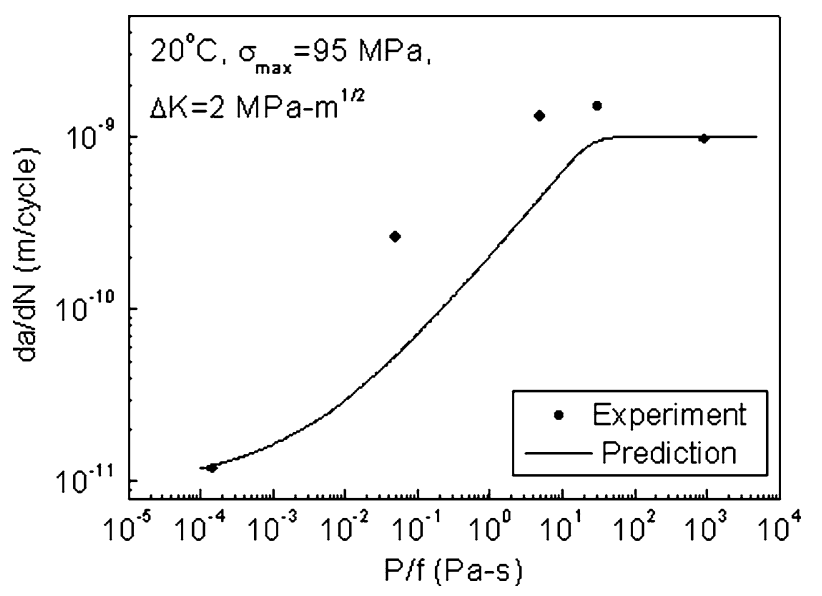

Fig. 16-Predicted fatigue-crack growth response as a function of water exposure based on the modified superposition model (Eqs. [14] and [15]), compared with experimental data, at a constant $\Delta K$ of $2 \mathrm{MPa} \sqrt{\mathrm{m}}$.

The predicted crack-growth response in environments based on the modified superposition model agrees well with the experiment results, as shown in Figure 18. In Figure 18(a), the crack-growth rates in ambient air at $20 \mathrm{kHz}$ and $30 \mathrm{~Hz}$ are examined. The predicted crackpropagation curve at $30 \mathrm{~Hz}$ in ambient air is actually the regression crack-growth curve at 30 and $1 \mathrm{~Hz}$, which represents saturation fatigue-crack growth rate. The predicted crack-growth rates at $20 \mathrm{kHz}$ in ambient air generally agree with the experimental results, although the crack-growth rates are modestly underpredicted. In Figure 18(b), the crack-growth rates at $20 \mathrm{kHz}$ in various environments with different water content are examined. The predicted crack-propagation curve at $20 \mathrm{kHz}$ in dry air is essentially the same as the regression crack-growth curve at $20 \mathrm{kHz}$ in dry air, which represents pure-mechanical fatigue-crack growth. The predicted crack-growth rates at $20 \mathrm{kHz}$ in liquid water generally agree with the experimentally measured crackgrowth rates, which are close to the regime of saturated environmental effect.

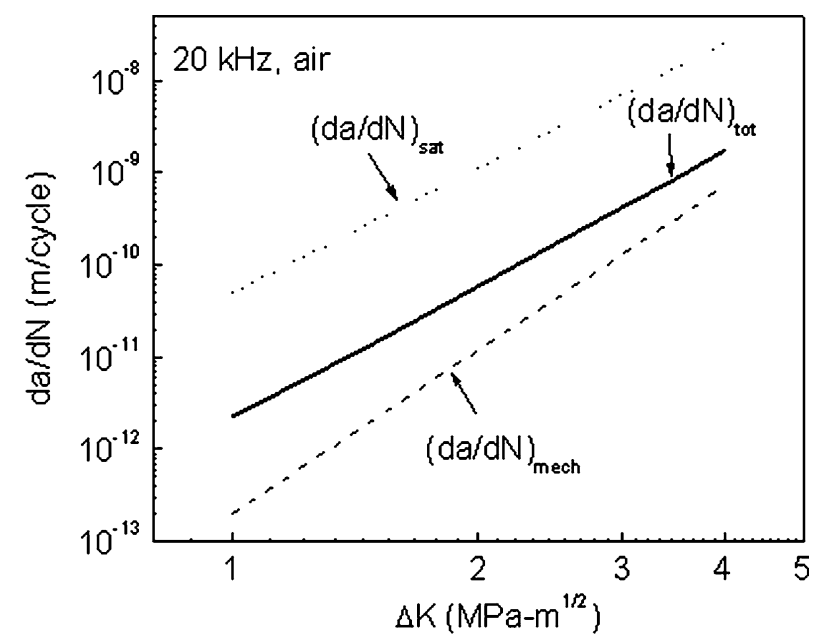

(a)

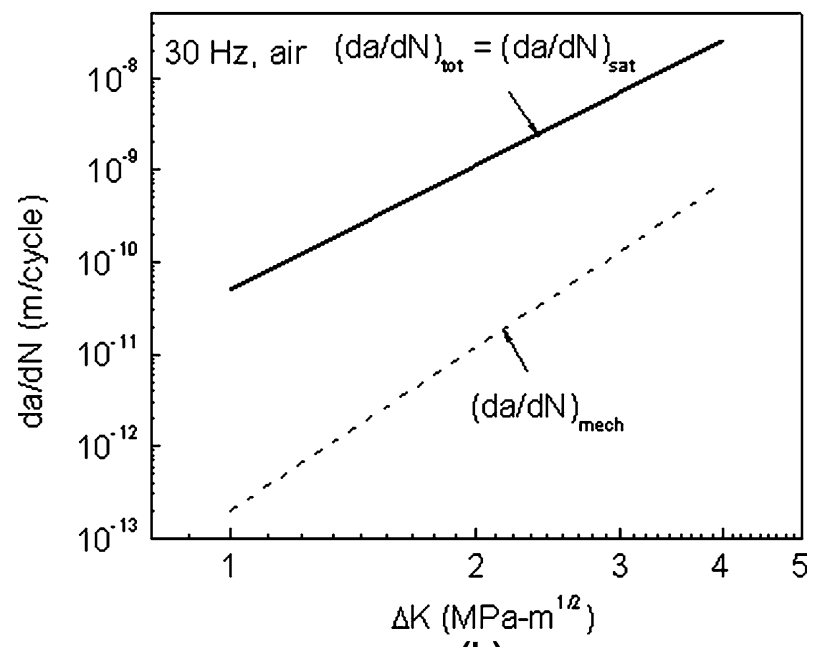

(b)

Fig. 17-Predicted environmental effect on fatigue-crack growth rate based on the modified superposition model (Eqs. [18] and [19]). (a) $20 \mathrm{kHz}$ in air and (b) $30 \mathrm{~Hz}$ in air. Here, $(d a / d N)_{\text {tot }}$ is the crackgrowth rate in the environment, $(d a / d N)_{\text {mech }}$ is the pure-mechanical fatigue-crack growth rate, and $(d a / d N)_{\text {sat }}$ is the saturation fatiguecrack growth rate.

These results indicate that a significant effect of frequency on fatigue-crack growth can be expected when E319 cast-aluminum alloy is tested in ambient air at ultrasonic frequency $(20 \mathrm{kHz})$ and conventional frequency (10 to $100 \mathrm{~Hz}$ ). Fatigue-crack growth rates increase with increasing water exposure and then become independent of water exposure when the environmental effect saturates. In ambient air, fatigue testing at $20 \mathrm{kHz}$ represents water exposure of $0.05 \mathrm{~Pa}$ s. In this condition, a hydrogen-assisted increase of fatigue-crack growth rate would occur, but the extent of environmental effect on crack-growth rate is moderate because the water exposure in this condition is well below the exposure for saturated environmental effect. On the other hand, fatigue testing at conventional frequencies (approximately 10 to $100 \mathrm{~Hz}$ ) represents water exposure of approximately 9 to $94 \mathrm{~Pa} \mathrm{~s}$, which is within, or very close to, the regime of saturated environmental effect. 


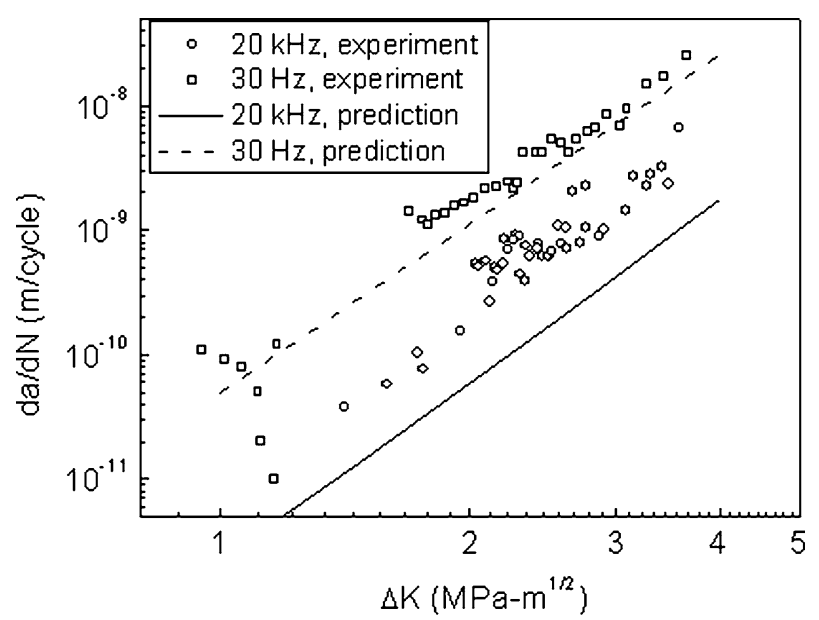

(a)

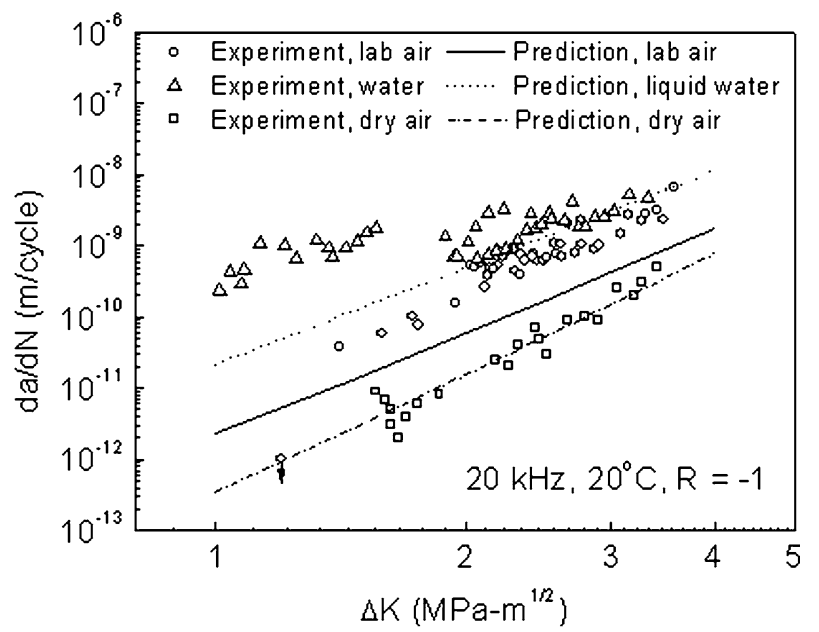

(b)

Fig. 18 - Predicted fatigue-crack growth response based on the modified superposition model (Eqs. [18] and [19]), compared with experimental data. (a) In ambient air, at $20 \mathrm{kHz}$ and $30 \mathrm{~Hz}$ and (b) at $20 \mathrm{kHz}$, in ambient air, liquid water, water vapor with 100 pet RH and dry air.

Since ultrasonic fatigue in ambient air represents less water exposure than conventional fatigue, the concentration of hydrogen responsible for an increase in crack-growth rate is less and, thus, the environmental fatigue-crack growth rate at ultrasonic frequency is lower than that at conventional frequency. The observed fatigue-crack growth rate is assumed to be the sum of the pure-mechanical fatigue-crack growth rate and the environmental fatigue-crack growth rate. Therefore, the observed crack-growth rate at ultrasonic frequency is lower than that at conventional frequency.

The correlation of fatigue-crack growth rate with water exposure provides a method to account for the influence of frequency that is caused by an environmental effect. Crack-growth behavior in vacuum (very low water exposure) and in air at low testing frequency (very high water exposure) can be treated, respectively, as the lower bound and the upper bound of crack-growth rates in environment. With these two bounds as references, crack-growth rates at any given frequency or water partial pressure can be estimated. When specimens are tested at $20 \mathrm{kHz}$ in laboratory air, the relative humidity might fluctuate from 20 to 90 pct. In this case, the water exposure varies from 0.02 to $0.1 \mathrm{~Pa} \mathrm{~s}$, and the corresponding crack-growth rate changes within a factor of 2 . When specimens are tested at $30 \mathrm{~Hz}$ in laboratory air, water exposure varies from 16 to $70 \mathrm{~Pa} \mathrm{~s}$, and the fatigue-crack growth rates are close to the saturation fatigue-crack growth rate when the relative humidity fluctuates from 20 to 90 pct. Therefore, at both ultrasonic frequency and conventional frequency, fluctuation of humidity in laboratory air does not significantly influence the fatigue-crack growth results.

In Engler-Pinto, Jr. et al., ${ }^{[16,35]}$ it was reported that the higher the yield strength, the greater the influence of the water on crack propagation for some cast Al-Si alloys. This is possibly because the higher-yield strength is obtained from peak-aged (T6) heat treatment, and the peak-aged aluminum alloy was found to be more sensitive to environmental effect than the overaged alloy. ${ }^{[26]}$ For these peak-aged alloys, the superposition model proposed by Wei et al. ${ }^{[15,29]}$ would be expected to give a better prediction of the effect of frequency on fatigue-crack growth rate. As shown in Figure 14, by assuming a linear correlation between $(d a / d N)_{\text {env }}$ and hydrogen concentration, the fatigue-crack growth rates in ambient air at 20 and $30 \mathrm{~Hz}$ differ by two orders of magnitude.

Because the crack-growth rate in environment, $(d a / d N)_{\text {tot }}$, is a function of temperature and Young's modulus when other parameters are constant, this model is also applicable for predicting environmental effect at elevated temperature. This issue is addressed in Section D.

\section{Mechanisms And Modeling of Temperature Effect on Fatigue-Crack Propagation}

Because the crack-growth rates have been observed to be influenced by the presence of water vapor in laboratory air, a question arises: is the effect of temperature on crack-growth rates related to an influence of temperature on the mechanical properties or to the temperature dependence of an environmental effect? The modified superposition model provides a basis to separately investigate the effect of temperature and environment. When temperature increases, the puremechanical fatigue-crack growth rates are expected to increase because of greater cyclic plasticity, greater accumulated fatigue damage, and, thus, lower cyclic strength of aluminum alloys. The environmental fatiguecrack growth rates are also expected to change with increasing temperature. Based on Eq. [18], the environmental contribution to fatigue-crack growth rate is proportional to $(\sqrt{E \sqrt{T}})^{-1}$. Therefore, $(d a / d N)_{\mathrm{env}}$ decreases with increasing temperature, which can be explained by the lower concentration of hydrogen available. At higher temperature, the molecular density of water vapor at a constant pressure is decreased due to volume expansion, and the number of water-vapor molecules that are transported through the crack by Knudsen flow is decreased. Thus, the concentration of 


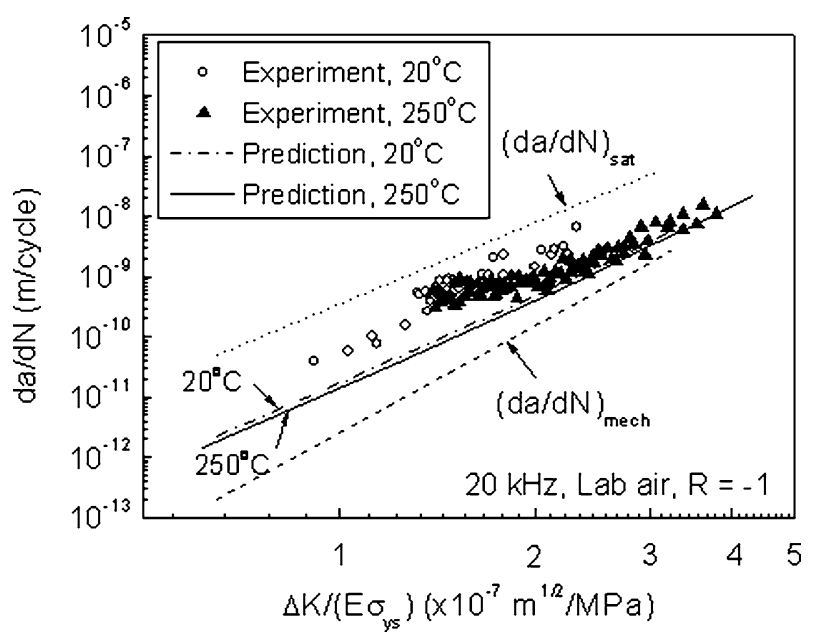

Fig. 19- Predicted crack growth rates at $20^{\circ} \mathrm{C}$ and $250{ }^{\circ} \mathrm{C}$ in air at $20 \mathrm{kHz}$ based on the modified superposition model (Eqs. [20] and [21]), compared with experimental results. Stress-intensity factor range is normalized by Young's modulus and yield strength.

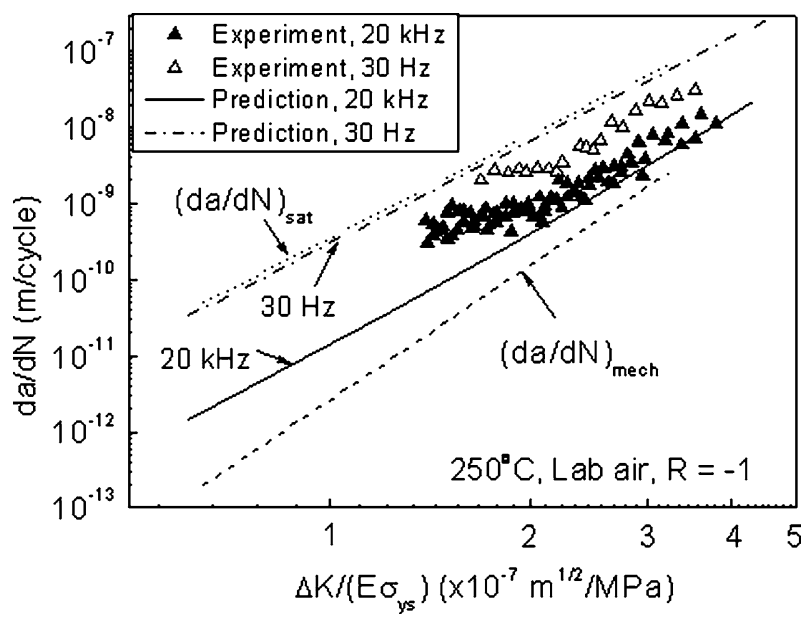

Fig. 20-Predicted fatigue-crack growth response at $250{ }^{\circ} \mathrm{C}$ at $20 \mathrm{kHz}$ and $30 \mathrm{~Hz}$ in laboratory air based on the modified superposition model (Eqs. [20] and [21]), compared with the experimental results.

water vapor and the concentration of hydrogen produced are decreased. On the other hand, Young's modulus decreases with increasing temperature, and this will increase crack-opening displacement and, in turn, make it easier for water molecules to migrate to the crack tip. Therefore, $(d a / d N)_{\text {env }}$ is expected to decrease with increasing temperature, but the decrease is offset by the simultaneously decreased Young's modulus.

To investigate the combined influence of temperature and frequency on crack propagation of E319 castaluminum alloy, Eqs. [18] and [19] were modified as follows to take into account the effect of temperature on fatigue-crack growth behavior:

$$
\text { For }\left(\frac{P}{f}\right)<\left(\frac{P}{f}\right)_{s} \text { : }
$$

$$
\begin{aligned}
\left(\frac{d a}{d N}\right)_{\mathrm{tot}}= & C_{1}^{\prime}\left(\frac{\Delta K}{E \sigma_{y s}}\right)^{m_{1}^{\prime}} \\
& +23 \times\left[C_{2}^{\prime}\left(\frac{\Delta K}{E \sigma_{y s}}\right)^{m_{2}^{\prime}}-C_{1}^{\prime}\left(\frac{\Delta K}{E \sigma_{y s}}\right)^{m_{1}^{\prime}}\right] \sqrt{\frac{\sigma_{\max } P}{E \sqrt{T} f}}
\end{aligned}
$$

$$
\begin{aligned}
\text { For }\left(\frac{P}{f}\right) \geq\left(\frac{P}{f}\right)_{s}: \\
\\
\qquad\left(\frac{d a}{d N}\right)_{\text {tot }}=C_{2}\left(\frac{\Delta K}{E \sigma_{y s}}\right)^{m_{2}^{\prime}}
\end{aligned}
$$

where $C_{1}^{\prime}$ and $m_{1}^{\prime}$ correspond to $(d a / d N)_{\text {mech }}$ after normalization of stress-intensity factor range $\left(C_{1}^{\prime}=5 \times 10^{29}, m_{1}^{\prime}=5.9\right)$ and $C_{2}^{\prime}$ and $m_{2}^{\prime}$ correspond to $(d a / d N)_{\text {sat }}$ after normalization of stress-intensity factor range $\left(C_{2}^{\prime}=8 \times 10^{20}, \quad m_{2}^{\prime}=4.5\right) . \quad(d a / d N)_{\text {tot }}$ is then

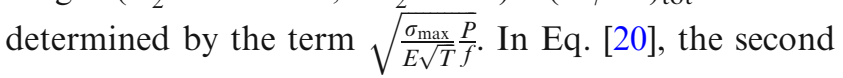
term on the right represents $(d a / d N)_{\mathrm{env}}$ as follows:

$$
\begin{aligned}
& \left(\frac{d a}{d N}\right)_{\mathrm{env}} \\
& =23 \times\left[C_{2}^{\prime}\left(\frac{\Delta K}{E \sigma_{y s}}\right)^{m_{2}^{\prime}}-C_{1}^{\prime}\left(\frac{\Delta K}{E \sigma_{y s}}\right)^{m_{1}^{\prime}}\right] \sqrt{\frac{\sigma_{\max }}{E \sqrt{T}} \frac{P}{f}}
\end{aligned}
$$

It would be helpful if $(d a / d N)_{\text {mech }}$ and $(d a / d N)_{\text {sat }}$ at $250{ }^{\circ} \mathrm{C}$ were known. However, this information is not available. So we assume that $(d a / d N)_{\text {mech }}$ and $(d a / d N)_{\text {sat }}$ obtained at room temperature apply for all temperatures after normalization of the stress-intensity factor range by Young's modulus and yield strength; i.e., at equivalent levels of $\Delta K /\left(E \sigma_{y s}\right), \quad\left(\frac{d a}{d N}\right)_{\text {mech }}^{250^{\circ} \mathrm{C}}=\left(\frac{d a}{d N}\right)_{\text {mech }}^{20^{\circ} \mathrm{C}}$, and $\left(\frac{d a}{d N}\right)_{\mathrm{sat}}^{250^{\circ} \mathrm{C}}=\left(\frac{d a}{d N}\right)_{\mathrm{sat}}^{20^{\circ} \mathrm{C}}$.

Based on Eqs. [20] and [21], the effect of temperature on fatigue-crack growth rates can be predicted. Figure 19 presents the predicted crack-growth rates at $20^{\circ} \mathrm{C}$ and $250{ }^{\circ} \mathrm{C}$ in air at $20 \mathrm{kHz}$, as a function of normalized stress-intensity factor range. Here, $(d a / d N)_{\text {mech }}$ and $(d a / d N)_{\text {sat }}$ are assumed to be independent of temperature and serve as the lower bound and upper bound of fatigue-crack growth rates. The crackgrowth rates in environment fall within the bounds. After normalization of the stress-intensity factor range, the fatigue-crack growth rate at $250{ }^{\circ} \mathrm{C}$ in air is slightly lower than that at $20^{\circ} \mathrm{C}$. This is because, according to Eq. [22], $(d a / d N)_{\text {env }}$ decreases with increasing temperature; however, the decrease in $(d a / d N)_{\mathrm{env}}$ is offset by the decrease of Young's modulus. Therefore, $(d a / d N)_{\text {env }}$ is not sensitive to the temperature change, which is consistent with the experimental observations. It is now clear that the effect on temperature on crack growth arises mainly from the effect of temperature on Young's modulus and yield strength. The environmental fatiguecrack growth rate decreases modestly with increasing temperature. 
The effect of frequency on fatigue-crack growth rate at elevated temperature can be modeled using Eqs. [20] and [21]. The effect of frequency at elevated temperature is still attributable to an environmental effect. When other parameters are constant, increasing testing frequency will decrease water exposure, and this will decrease $(d a / d N)_{\text {env }}$ and, therefore, $(d a / d N)_{\text {tot }}$. The predicted fatigue-crack growth rates at $250{ }^{\circ} \mathrm{C}$ at testing frequency of $20 \mathrm{kHz}$ and $30 \mathrm{~Hz}$ are presented in Figure 20. It can be seen that, at $250{ }^{\circ} \mathrm{C}$, the predicted crack-growth rates at $20 \mathrm{kHz}$ are approximately an order of magnitude lower than the predicted crackgrowth rates at $30 \mathrm{~Hz}$. At $250{ }^{\circ} \mathrm{C}$, comparison of experimental results to the model indicates that the predicted difference in crack-growth rates between $20 \mathrm{kHz}$ and $30 \mathrm{~Hz}$ is greater than the experimental observations, but the trend of greater crack-growth rates at lower frequency agrees well with the experimental results.

\section{CONCLUSIONS}

The fatigue-crack propagation behavior of E319 cast-aluminum alloy was determined at both $20 \mathrm{kHz}$ and $30 \mathrm{~Hz}$ in air at $20^{\circ} \mathrm{C}$ and $250{ }^{\circ} \mathrm{C}$. The major conclusions are summarized as follows.

1. The crack-growth rate of E319 cast-aluminum alloy in laboratory air at $20 \mathrm{kHz}$ is lower than at $30 \mathrm{~Hz}$ at both $20^{\circ} \mathrm{C}$ and $250{ }^{\circ} \mathrm{C}$. The difference in fatiguecrack growth rates in air between $20 \mathrm{kHz}$ and $30 \mathrm{~Hz}$ is attributable to an environmental effect.

2. The presence of water in air was found to increase the fatigue-crack growth rate. At a given stressintensity factor range, $\Delta K$, fatigue-crack growth rate increases with water exposure, $P / f$, until it reaches the maximum value when saturation of the environmental contribution occurs. Fatigue testing at $30 \mathrm{~Hz}$ in air represents higher water exposure than fatigue testing at $20 \mathrm{kHz}$, and, therefore, the crack-growth rates at $30 \mathrm{~Hz}$ are higher than that at $20 \mathrm{kHz}$. The dependence of crack-growth rate on water exposure closely follows the dependence of hydrogen concentration on water exposure, which supports the assumption that the enhancement of crack-growth rate caused by environment is determined by the concentration of hydrogen in the plastic zone.

3. The effect of frequency and environment on fatiguecrack growth rate is characterized by a modified superposition model. In this model, hydrogeninduced increase of fatigue-crack growth rate is assumed to be proportional to the square root of hydrogen concentration, which is determined by the transport rate of water molecules from the surrounding environment to the crack tip. Based on this model, fatigue-crack growth rates over the entire range of $\Delta K$ in various environments with different water exposure can be predicted, and the predictions generally agree well with the experimental observations.
4. The fatigue-crack growth rate at all temperatures can be successfully described by a universal version of the modified superposition model, in which crack-growth rate is a function of normalized stress-intensity factor range, $\Delta K /\left(E \sigma_{y s}\right)$. This model provides a framework to separately characterize the intrinsic effect of temperature on mechanical properties and the effect of environment at elevated temperature. The effect of temperature on fatigue resistance primarily results from the intrinsic effect of temperature on Young's modulus and yield strength. The environmental contribution to fatigue-crack growth rates modestly decreases with increasing temperature.

5. These results show that environmental effects need to be considered when ultrasonic fatigue is used to generate fatigue data for modeling the fatigue property of the aluminum-alloy components that operate under conventional loading frequency in service. A modified superposition model was proposed to characterize the hydrogen-induced increase of fatigue-crack growth rates in E319 cast-aluminum alloy. Although based on numerous assumptions, this model provides a basis for investigation of frequency effect on fatigue behavior due to environmental effect at both room temperature and elevated temperature.

\section{ACKNOWLEDGMENTS}

Financial support provided by the United States National Science Foundation (Grant No. DMR 0211067) and Ford Motor Company is gratefully acknowledged. The authors thank C.J. Torbet for his assistance with environmental control, A. Shyam for his advice on small crack-growth testing, and J. Yi for helpful discussions.

\section{REFERENCES}

1. M.J. Caton, J.W. Jones, J.M. Boileau, and J.E. Allison: Metall. Mater. Trans. A, 1999, vol. 30A, pp. 3055-68.

2. M.J. Couper, A.E. Neeson, and J.R. Griffiths: Fatigue Fract. Eng. Mater. Struct., 1990, vol. 13 (3), pp. 213-27.

3. B. Skallerud, T. Iveland, and G. Harkegard: Eng. Fract. Mech., 1993, vol. 44 (6), pp. 857-74.

4. X. Zhu, A. Shyam, J.W. Jones, H. Mayer, J.V. Lasecki, and J.E. Allison: Int. J. Fatigue, 2006, vol. 28 (11), pp. 1566-71.

5. L.E. Coffin: in Ultrasonic Fatigue, J.M. Wells, O. Buck, L.D. Roth, and J.K. Tien, eds., TMS-AIME, Warrendale, PA, 1982, p. 423.

6. C. Laird and P. Charlsey: in Ultrasonic Fatigue, J.M. Wells, O. Buck, L.D. Roth, and J.K. Tien, eds., TMS-AIME, Warrendale, PA, 1982, p. 183.

7. J.K. Tien: in Ultrasonic Fatigue, J.M. Wells, O. Buck, L.D. Roth, and J.K. Tien, eds., TMS-AIME, Warrendale, PA, 1982, p. 1.

8. B. Holper, H. Mayer, A.K. Vasudevan, and S.E. Stanzl-Tschegg: Int. J. Fatigue, 2003, vol. 25 (5), pp. 397-411.

9. B. Holper, H. Mayer, A.K. Vasudevan, and S.E. Stanzl-Tschegg: Int. J. Fatigue, 2004, vol. 26 (1), pp. 27-38.

10. J. Ruiz and M. Elices: Vacuum, 1994, vol. 45 (10-11), pp. 1069-71.

11. S.E. Stanzl, H.R. Mayer, and E.K. Tschegg: Mater. Sci. Eng., A, 1991, vol. 147 (1), pp. 45-54. 
12. M. Papakyriacou, H. Mayer, U. Fuchs, S.E. Stanzl-Tschegg, and R.P. Wei: Fatigue Fract. Eng. Mater. Struct., 2002, vol. 25 (8-9), pp. 795-804.

13. R.S. Piasick and R.P. Gangloff: Metall. Trans. A, 1991, vol. 22A, pp. 2415-28.

14. J. Petit, G. Henaff, and C. Sarrazin-Baudoux: Environmentally Assisted Fatigue in Gaseous Atmosphere, Elsevier Press, Amsterdam, 2003, pp. 211-80.

15. M. Gao, P.S. Pao, and R.P. Wei: Metall. Trans. A, 1988, vol. 19A, pp. $1739-50$.

16. C.C. Engler-Pinto, Jr., R.J. Frisch, Sr., J.V. Lasecki, J.E. Allison, X. Zhu, and J.W. Jones: SAE Technical Paper 2006-01-0540, SAE International, Warrendale, PA.

17. X. Zhu: Ph.D. Dissertation, University of Michigan, Ann Arbor, MI, 2007.

18. X. Zhu, J.W. Jones, and J.E. Allison: Metall. Mater. Trans. A, 2007, vol. 38A, doi:10.1007/s11661-008-9631-1.

19. J. Huang, J.E. Spowart, and J.W. Jones: Fatigue Fract. Eng. Mater. Struct., 2006, vol. 29 (7), pp. 507-17.

20. A.T. Shyam, S.K. Jha, J.M. Larsen, M.J. Caton, C.J. Szczepanski, T.M. Pollock, and J.W. Jones: Superalloys, 2004, Champion, PA, 2004.

21. J.Z. Yi, C.J. Torbet, Q. Feng, T.M. Pollock, and J.W. Jones: Mater. Sci. Eng., A, 2007, vol. 443 (1-2), pp. 142-49.

22. R.E. Peterson: Stress Concentration Factors, John Wiley \& Sons, New York, NY, 1974, p. 37.

23. Q. Feng, Y.N. Picard, H. Liu, S.M. Yalisove, G. Mourou, and T.M. Pollock: Scripta Mater., 2005, vol. 53 (5), pp. 511-16.
24. J.C. Newman and I.S. Raju: Eng. Fract. Mech., 1981, vol. 15, pp. 185-92.

25. Y.J. Ro, S.R. Agnew, and R.P. Gangloff: VHCF-4, TMS, Warrendale, PA, 2007.

26. J. Petit and C. Sarrazin-Baudoux: Int. J. Fatigue, 2006, vol. 28 (11), pp. 1471-78.

27. R.P. Gangloff: Hydrogen-Assisted Cracking, Elsevier Press, Amsterdam, 2003, pp. 31-101.

28. C.C. Engler-Pinto, Jr., J.V. Lasecki, J.M. Boileau, and J.E. Allison: SAE Technical Paper 2004-01-1029.

29. R.P. Wei: Fatigue Fract. Eng. Mater. Struct., 2002, vol. 25 (8-9), pp. $845-54$

30. E.A. Mason and A.P. Malinauskas: Gas Transport in Porous Media: The Dusty-Gas Model, Elsevier Press, Amsterdam, 1983.

31. R.P. Wei, P.S. Pao, R.G. Hart, T.W. Weir, and G.W. Simmons: Metall. Mater. Trans. A, 1980, vol. 11A, pp. 151-58.

32. A.D.B. Gingell and J.E. King: Acta Mater., 1997, vol. 45 (9), pp. $3855-70$.

33. N.J.H. Holroyd and D. Hardie: Corros. Sci., 1983, vol. 23 (6), pp. 527-31.

34. D.J. Fisher: Hydrogen Diffusion in Metals-A 30-Year Retrospective, Scitec Publications Ltd., Uetikon-Zürich, Switzerland, 1999, pp. $30-31$.

35. C.C. Engler-Pinto, Jr., R.J. Frisch, Sr., J.V. Lasecki, H. Mayer, and J.E. Allison: $V H C F-4$, TMS, Warrendale, PA, 2007. 